\title{
Endowment Effects in the Field: Evidence from India's IPO Lotteries*
}

\author{
Santosh Anagol ${ }^{\dagger} \quad$ Vimal Balasubramaniam ${ }^{\ddagger} \quad$ Tarun Ramadorai $^{\S}$ \\ June 12, 2016
}

\begin{abstract}
Winners of randomly assigned initial public offering (IPO) lottery shares are significantly more likely to hold these shares than lottery losers 1, 6, and even 24 months after the random allocation. This effect persists in samples of wealthy and highly active investors, suggesting along with additional evidence that this type of "endowment effect" is not solely driven by portfolio inertia or wealth effects. The effect decreases as experience in the IPO market increases, but persists even for the most experienced investors. These results suggest that agents' preferences and/or beliefs about an asset are not independent of ownership, providing field evidence derived from the behavior of 1.5 million Indian stock investors which is in line with the large laboratory literature documenting endowment effects. We evaluate the extent to which prominent models of endowment effects and/or investor behavior can explain our results. A combination of inattention and non-standard preferences (realization utility) or non-standard beliefs (salience based probability distortions) appears most consistent with our findings.
\end{abstract}

${ }^{*}$ We gratefully acknowledge the Alfred P. Sloan Foundation for financial support, and the use of the University of Oxford Advanced Research Computing (ARC) facility for processing. We thank Sushant Vale for dedicated research assistance, and Eduardo Azevedo, Pedro Bordalo, John Campbell, Nicola Gennaioli, David Gill, Raj Iyer, Dean Karlan, Judd Kessler, Ulrike Malmendier, Ian Martin, Andrei Shleifer, Dmitry Taubinsky, Shing-Yi Wang and seminar participants at the AFA Annual Meetings, Bocconi, Imperial College Business School, the Institute for Fiscal Studies, Goethe University, the London School of Economics, and London Business School for comments.

${ }^{\dagger}$ Anagol: Wharton School of Business, Business Economics and Public Policy Department, University of Pennsylvania, and Oxford-Man Institute of Quantitative Finance. Email: anagol@wharton.upenn.edu

${ }^{\ddagger}$ Balasubramaniam: Saïd Business School, Oxford-Man Institute of Quantitative Finance, University of Oxford, Park End Street, Oxford OX1 1HP, UK. Email: vimal.balasubramaniam@sbs.ox.ac.uk

${ }^{\S}$ Ramadorai: Saïd Business School, Oxford-Man Institute of Quantitative Finance, University of Oxford, Park End Street, Oxford OX1 1HP, UK and CEPR. Email: tarun.ramadorai@sbs.ox.ac.uk 


\section{Introduction}

A large and influential laboratory literature documents that the act of owning an object has an important causal effect on the subject's subsequent valuations of the object. These results call into question a basic assumption underlying most neoclassical economic theory that preferences and beliefs are independent of ownership, and have resulted in the development of new theoretical ideas to explain the laboratory evidence (Thaler, 1980; Köszegi and Rabin, 2006; Bordalo et al., 2012). An important challenge for this area of work is the extent to which such "endowment effects" manifest themselves in market settings outside the laboratory, and if they do, whether they can be explained by the new theoretical models. Two particular reasons to heed caution in extrapolating from lab experiments documenting endowment effects to markets outside of the lab are that (1) market participants are likely to have more relevant experience than laboratory subjects, and (2) findings of endowment effects in the lab appear to be sensitive to experimental procedures, rendering it difficult to determine which experimental procedures map most closely to markets outside of the laboratory (Zeiler and Plott, 2004).

List (2003) and List (2011) are two recent studies that move outside the lab to test for endowment effects, using a field experimental design with sports memorabilia and collectible pin traders as subjects. Traders are randomly assigned to own one of two pieces of sports memorabilia or collector's pins, and subsequently given the opportunity to trade the objects in the marketplace. Given the random assignment, trading rates of less than 50 percent constitute evidence of endowment effects. Both studies find substantial endowment effects amongst inexperienced traders, but strongly attenuated endowment effects amongst the most experienced participants. ${ }^{1}$ The latter result is provocative, because it suggests that the ample evidence on endowment effects from lab experiments has limited relevance in market settings

\footnotetext{
${ }^{1}$ The main difference between these two studies is that List (2011) induces experimental variation in the level of experience traders have (by randomly encouraging trade and then conducting the endowment experiment one year later), while List (2003) uses the naturally occurring variation in experience (i.e., whether a trader is a dealer in the market or has made many trades prior to the experiment).
} 
outside the lab, which may be populated by experienced participants. ${ }^{2}$

The research design employed in List (2003) and List (2011) is appealing because it embeds a field market setting (i.e., traders in a naturally occurring market) within an experimental design that allows for the clean estimation of endowment effects. But the desire to maintain experimental control whilst simultaneously operating in the field naturally limits the scope (in terms of markets studied) and size (in terms of subjects) of these particular field experiments - they focus on two specialized markets and use small samples (between 60 and 74 subjects per experiment). While these limitations do not threaten the internal validity of these studies' conclusions, it is difficult to judge whether the results from these specific markets can be generalized to many important markets where we might expect endowment effects to operate. ${ }^{3}$

In this paper, we broaden the scope of field tests of endowment effects, exploiting a natural experiment that provides randomized variation in endowments to millions of market participants outside of the lab. As a result of regulatory requirements, in many cases Indian initial public offering (IPO) shares are randomly assigned to applicants. Under the assumption of minimal wealth effects (which we discuss in detail later), winners and losers in these IPO lotteries should have virtually identical preferences, beliefs, and information sets before and after the shares are allotted. While lottery losers do not have the opportunity to buy the shares at the IPO issue price, once the stock begins to trade freely, both winner and loser

\footnotetext{
${ }^{2}$ We emphasize the List (2003) and List (2011) studies because they involve traders making decisions regarding the naturally occurring good in the relevant marketplace (e.g. decisions about baseball cards at a sports memorabilia show). Other relevant studies, which integrate lab and field procedures, include List (2004), who finds endowment effects in the decision to trade or hold randomly assigned chocolate bars or mugs amongst inexperienced (but not among experienced) attendees at a sports memorabilia show. A related literature tests whether endowment effects can be harnessed to improve the effectiveness of incentives, assigning a control group a standard incentive to be paid after a good performance, and a treatment group an upfront incentive that is taken away if performance is poor. Hossain and List (2012) and Fryer Jr et al. (2012) find this framing of incentives improves manufacturing worker and teacher performance respectively, while Levitt et al. (2012) finds no effect of this type of framing of test score contingent payments on student test scores. These results suggest the relevance of endowment effects in the field, but may be less relevant for endowment effects in product and asset markets.

${ }^{3}$ As List (2011) notes, the small sample sizes also cause relatively large confidence intervals around the endowment effect estimates, making it difficult to pinpoint the amount by which experience attenuates the endowment effect.
} 
groups have equal opportunities to trade the stock. Given the equivalence of information sets and background characteristics induced by the random assignment, we should expect that the holdings of this randomly allocated stock across the two groups should converge rapidly over time. If endowment effects are important, however, we should expect a divergence in the behavior of the randomly chosen winners and losers. ${ }^{4}$

We document that the winners of IPO lotteries are substantially more likely to hold the randomly allocated IPO shares for many months and even years after the allocation. In our main results, we find that 62.4 percent of IPO winners hold the IPO stock at the end of the month after listing, while only 1 percent of losers hold the stock. Six months after the lottery assignment the gap decreases slightly, to 46.6 percent of winners holding the stock and 1.6 percent of the losers holding the stock, but even 24 months after the random assignment we find that winners are 35 percentage points more likely to hold the IPO stock than losers. We term this effect an "endowment effect," with analogies to the laboratory literature, because the fact that winners of these lotteries are randomly endowed with the IPO stock appears to cause them to be more likely to hold stock than losers.

We investigate whether this endowment effect attenuates substantially for the most experienced traders in our setting, as in List (2003). We compare the strength of this endowment effect across investors with different levels of experience in the IPO market measured in a number of different ways. For example, for each investor, we observe the number of IPOs they have previously been allotted over the past 10 years, a measure of experience which varies from 0 previous experiences up to 30 previous experiences at the $90^{\text {th }}$ percentile of the distribution. Consistent with List (2003), we find a strong negative correlation (which is robust to the inclusion of various controls) between this experience measure and the difference in holdings between lottery winners and losers. However, while List (2003) finds that endowment effects become negligible amongst his sample of experienced traders (sports

\footnotetext{
${ }^{4}$ Throughout the paper we refer to the difference in propensity to hold the IPO stock across IPO winners and losers as an endowment effect, to be consistent with most of the laboratory literature which refers to this type of exchange asymmetry as an endowment effect. We do not use the term endowment effect to suggest any particular theoretical mechanism underlying our empirical findings.
} 
card dealers and very experienced non-dealers), we find substantial endowment effects even amongst investors who have participated in over 30 IPOs - on average these highly experienced winners still hold 27 percent of their lottery allotments at the end of the month of randomly receiving the IPO, while losers hold 7 percent of the initial allocation. ${ }^{5,6}$

We next explore the extent to which prominent theories of endowment effects and/or investor behavior can explain our empirical results. ${ }^{7}$ Theories in the first category (the "standard expected utility" category) assume that individuals have preferences and beliefs that are independent of endowments, but explore whether some other feature of the setting (e.g., wealth effects or inertial behavior) could cause IPO winners to prefer greater holdings of the IPO stock. Theories in the second category consider the role of preferences where endowments directly affect valuations (e.g., reference dependent preferences with loss aversion), or the possibility that endowments might affect agents' beliefs (e.g., salience-based probability distortions). While the lab literature has attempted to completely rule out certain mechanisms while testing for the presence of others, we note that in our field setting (and very likely in most field settings) various mechanisms from both categories could be at play, and decisively identifying a single theoretical explanation of our results would require additional experimental variation. Our focus is on applying each theory to our empirical setting, deriving testable predictions, and then evaluating whether our major empirical facts are consistent with those predictions.

We provide a comprehensive discussion of issues pertaining to the first category of explanations later in the paper, but note two major examples of such features here, namely,

\footnotetext{
${ }^{5}$ These results are also interesting in light of Haigh and List (2005), who find that professional futures traders exhibit greater myopic loss aversion and raise the possibility that market experience might exacerbate behavioral anomalies. Our evidence rejects the idea that more experienced market participants exhibit the endowment effect anomaly more strongly.

${ }^{6} \mathrm{We}$ also exploit the random assignment of previous lotteries to provide a sharper comparison of whether the behavior of more experienced lottery players converges more than that of less experienced lottery players, and find evidence that those who have previously won IPOs have smaller estimated endowment effects in the future. Similar to the experience correlations discussed above, however, the rate of learning appears to be slow. Overall, the evidence from these two types of analyses suggests that while experience does substantially reduce this particular endowment effect, it seems unlikely that experience eliminates this anomaly completely.

${ }^{7}$ See Ericson and Fuster (2014) for a review of laboratory experiments that estimate the endowment effect and attempt to distinguish causal mechanisms.
} 
wealth effects and inertial behavior. The winners in our experiment receive a wealth shock since Indian IPOs are typically under priced relative to the first price at which they trade on the market. However, we argue that the magnitude of this shock is unlikely to explain the divergence in winner-loser holding patterns for a number of reasons. Most importantly, the actual gains in the treatment IPO (on average US\$62) are small relative to the amount of cash participants are required to place in escrow in order to participate in these lotteries in the first place (on average US\$ 1,750), making it unlikely that lottery winnings are relieving a major wealth constraint. Moreover, we find that endowment effects are similar for IPOs associated with low and high wealth shocks (i.e., the listing return on the IPO).

Inertial behavior by investors is a second potentially important explanation for our results, involving no effect of endowments on valuations or beliefs. (S,s) models of optimal inaction in the presence of fixed costs have been studied in the economics literature for many decades. In our setting, such fixed costs might include brokerage commissions, transactions costs, taxes, or cognitive processing costs such as the cost of accessing accounts and placing trades. ${ }^{8}$ Given that our main results (that lottery winners tend to hold the stock while losers do not) comes from inaction on the part of investors in the IPO stock, inertia is naturally a good description of their behavior. It is important, however, to draw a distinction between inertial behavior that is specific to the IPO stock, and inertial behavior affecting behavior in the portfolio as a whole. If our results are due to the fact that investors are inert in their entire portfolios, this would obviously reduce the relevance of our study to other settings where endowment effects may be present. However, if the inertial behavior is specific to the IPO stock, it is interesting to further evaluate models of preferences, beliefs, or information that might generate the endowment effects that we observe.

A number of facts suggest that inertial behavior at the portfolio level is unlikely to generate the endowment effects we observe. First, we find a large endowment effect even

\footnotetext{
${ }^{8}$ Recent papers have attempted to characterize optimal decision rules in the presence of both standard fixed costs and information processing costs - see, for example, Alvarez et al. (2013) and Abel et al. (2013). Andersen et al. (2015) attempt an empirical characterization of both inattention and inertia using Danish households' mortgage refinancing decisions, and find that both are important factors.
} 
when we restrict our sample to those winners and losers who make more than 20 trades (in non-IPO stocks) in each of the months in which we measure the effect. Thus, the results are not being driven by a subset of investors who are mainly inactive. ${ }^{9}$ Second, when we further restrict the sample to winners and losers who recently made a trade (in non-IPO stocks) of sizes less than or equal to the size of the initial random endowment of the IPO, we find that our point estimate of endowment effect is very similar, suggesting that our results are not being driven by the IPO position being "too small" to warrant action. Finally, in related work we find that lottery winners have a higher trading intensity (of the non-IPO stocks in their portfolio) than lottery losers, and tend to tilt their portfolios in the direction of the industry sector in which the IPO stock is situated, suggesting that winning the lottery appears to reduce the (cognitive) transaction costs associated with making trades (Anagol et al., 2015).

Turning to the second category of explanations, we consider a series of theoretical models that have either been prominent explanations of endowment effects or of related investor behavior (such as the disposition effect) in past work. Our goal is not to conclusively determine which model explains all of our empirical facts, but instead, to provide guidance for future empirical work that tests theoretical mechanisms that might drive endowment effects in the field.

Amongst endowment effect explanations where endowments do have a causal effect on valuations, the most prominent mechanism explored in the literature is the idea that agents have reference dependent utility with loss-aversion. In this framework agents receive utility from potential transactions relative to a reference point, with the particular form of the reference point having an important impact on predicted behavior. Kőszegi and Rabin (2006) (KR) present a theory where the reference point is set by an agent's recently formed expectations about future outcomes, and we consider three models in this class. These

\footnotetext{
${ }^{9}$ This finding also assuages concerns that our results are being driven by "trade uncertainty" - the idea that investors are uncomfortable with trading in general and therefore stick to the status quo (Engelmann and Hollard, 2010).
} 
models contain increasingly complex formulations of the reference point, culminating in a setup which more closely matches features of our real-world experimental environment. In each case, we find the range of parameter values (for the extent of loss aversion, the expected return on the stock, and the expected probability of winning the IPO lottery) where the same agent would choose to hold the stock if they won the lottery, but not purchase the stock if they lost the lottery. ${ }^{10}$ We discuss these models in detail in the paper and the Appendix, but, in general, find that they deliver narrow parameter ranges in which the endowment effect plan is a PE, or generate auxiliary predictions that are not supported by the data.

We next consider a number of alternative models including the "aversion to bad deals" model of Weaver and Frederick (2012), the realization utility model of Shefrin and Statman (1985) and Barberis and Xiong (2012), and the salience model of Bordalo et al. (2012). The bad deals and realization utility models can generate an endowment effect; however, both models deliver the prediction that the size of the endowment effect varies inversely with the size of the initial listing gain on the IPO stock. This prediction is strongly refuted by the data, where we find that the largest endowment effects occur for IPOs with closer to zero gains, with smaller endowment effects observed in IPOs with either negative or highly positive listing gains.

We find that the salience model of Bordalo et al. (2012) is able to plausibly generate the behavior of winners post-listing. However, once we embed salience-based decision making in a more realistic setup which includes the initial application lottery, we find that it is unable to generate the endowment effect that we see, primarily because the model (as well as many of the other models that we consider) is unable to provide an explanation for why lottery losers consistently choose not to purchase the stock on the open market. ${ }^{11}$ To explain this

\footnotetext{
${ }^{10}$ In the language of Köszegi and Rabin (2006), we find the range of parameter values where we would observe an endowment effect in our experiment because agents are playing their "personal equilibrium" strategies. In several cases, we also consider whether the plan generates the highest expected utility of all possible PE plans, i.e., whether it is a "preferred personal equilibrium" or PPE.

${ }^{11}$ We note that this is a new fact to add to the broad literature on the disposition effect - this is primarily because this literature has not thus far been able to observe a "control" group of investors with similar background characteristics that did not own the stock.
} 
feature of the data, we discuss a simple model of attention allocation in which lottery losers are assumed to be completely inattentive to the stock, post-lottery. One possible micro foundation for this assumption is that winning the stock in the lottery provides "exposure" to the stock, which keeps it in the attention set of winners; but since losers do not receive this exposure, it remains out of the attention set for them (see, for example, Bordalo et al. (2015)). Overall, we conclude that it will require a combination of the features present in the different models we consider in order to provide a fuller explanation of the rich set of facts that we uncover in our natural experiment.

\section{The Experiment: India's IPO Lotteries}

As with many other details of regulation in the country, the Indian regulatory process for IPOs is quite complex. Several papers (e.g., Anagol and Kim, 2012; Campbell et al., 2015) have used this complexity of the Indian regulatory process to cleanly identify a range of economic phenomena. Our experiment uses the Indian retail investor IPO lottery as a naturally occurring setting in which some agents are randomly endowed with an asset while others are not, and we can observe agents' choices to trade the asset following the random endowment. In this section we describe the circumstances in which these lotteries occur (including a specific example), and in the next section describe how they can be used to estimate endowment effects. We provide the precise details of the IPO lottery process and associated regulations in Appendix Section A.1.

To summarize, these IPO lotteries arise in situations in which an IPO is oversubscribed, and the use of a proportional allocation rule to allocate shares would violate the minimum lot size of shares set by the firm. In these situations, the lottery is run to give investors who applied for shares their proportional allocation in expectation. The outcome of the lottery is that some investors who applied receive the minimum lot size (this is the treatment group), while others who applied receive zero shares (the control group). The fundamental reason 
for the lottery is that in India, regulations require that a firm must set aside $30 \%$ or $35 \%$ of its shares (depending on the type of issue) to be available for allocation to retail investors at the time of IPO. For the purposes of the regulation, "retail investors" are defined as those with expressed share demands beneath a preset value. At the time of writing, this preset value is set by the regulator at Rs. 200,000 (roughly US $\$ 3,400$ ); this value has varied over time (see Appendix Section A.1).

The share allocation process in an Indian IPO begins with the lead investment bank, which sets an indicative range of prices. The upper bound of this range (the "ceiling price") cannot be more than $20 \%$ higher than the lower bound (or "floor price"). Importantly, a minimum number of shares (the "minimum lot size") that can be purchased at IPO is also determined at this time. All IPO bids (and ultimately, share allocations) are constrained to be integer multiples of this minimum lot size.

Retail investors can submit two types of bids for IPO shares. The simplest and most frequent type of bid is a "cutoff" bid, where the retail investor commits to purchasing a stated multiple of the minimum lot size at the final issue price that the firm chooses within the price band. ${ }^{12}$ To submit the bid, the retail investor deposits an amount into an escrow account, which is equal to the ceiling of the price band multiplied by the desired number of shares. If the investor is allotted shares, and the final issue price is less than the ceiling price, the difference between the deposited and required amounts is refunded to the investor. The remaining investors in our sample submitted "full demand schedule" bids, i.e., the number of lots that they would like to purchase at each possible price within the indicative range, once again depositing in escrow the maximum monetary amount consistent with their demand schedule at the time of submitting their bid, with a refund processed for any difference between the final price and the amount placed in escrow.

Once all bids have been submitted the total levels of demand and supply of shares are set (see Appendix Section A.1 for additional details), and regulation determines how shares

\footnotetext{
${ }^{12} 93 \%$ of applicants in our sample submit cut-off bids.
} 
will be allotted in the case that demand exceeds supply.

We define retail over subscription $v$ as the ratio of total retail demand for a firm's shares to total supply of shares by the firm to retail investors, i.e., the total number of shares made available by the firm for retail investors to purchase.

There are then three possible cases:

1. $v \leq 1$. In this case, all retail investors are allotted shares according to their demand schedules.

2. $v>1$, and shares can be allocated to investors in proportion to their stated demands without any violation of the minimum lot size constraint. There is no lottery involved in this case.

3. $v>>1$ (the issue is substantially oversubscribed), and a number of investors under a proportional allocation scheme would receive an allocation which is lower than the minimum lot size. This constraint cannot be violated by law, and therefore, all such investors are entered into a lottery. In this lottery, the probability of receiving the minimum lot size is proportional to the number of shares in the original bid and lottery applicants receive their proportional allotment in expectation. ${ }^{13}$

This third case, in which the lottery takes place, provides the random variation that we exploit to test for the endowment effect. Far from being an unusual occurrence, in our sample alone (which is a subset of all IPOs in the Indian market over the sample period), roughly 1.5 million Indian investors participate in such lotteries over the 2007 to 2012 period in the set of 54 IPOs that we study.

The time line of the application and allotment process is as follows. Applications are received over a two-day period termed the "subscription period." Shares are allotted to the winner's accounts approximately 12 days after the applications are received. The shares

\footnotetext{
${ }^{13}$ Appendix Section A.3 shows a mathematical derivation of the probabilities of winning allotments based on the level of excess demand.
} 
typically list approximately 21 days after the subscription period. Refunds of the escrow amounts begin to be processed after the allotments are made, usually 14 days after the allotments are made, so it is possible that the refunds are made after the shares are listed (we discuss how this might affect our inferences later). Lottery losers receive a complete refund on their escrow amounts.

\subsection{An Example: Barak Valley Cements IPO Allocation Process}

Barak Valley Cements' IPO opened for subscription on October 29, 2007, and remained open for subscription through November 1, 2007. The stock was simultaneously listed on the National Stock Exchange (NSE) and the Bombay Stock Exchange (BSE) on November 23, 2007. The listing price of the stock was Rs. 42 per share, and the stock closed on the first day of listing at Rs. 56.05 per share, for a $33.45 \%$ listing day gain. The retail over subscription rate $v$ for this issue was 37.62. Given this high $v$, all retail investors that applied for this IPO were entered into a lottery.

Table 1 shows the official retail investor IPO allocation data for Barak Valley Cements. ${ }^{14}$ Each row of column $(0)$ of the table shows the share category $c$, associated with a number of shares applied for given in column (1), which, given the minimum lot size $x=150$ for this offer is just $c x$. In this case, the total number of share categories $(C)$ equals 15 , meaning that the maximum retail bid is for 2,250 shares. This is because $C=16$ would give a number of 2,400 shares, and a maximum subscription amount of Rs. 100,800 at the listing price of Rs. 42. This maximum subscription amount would violate the prevailing (in 2007) regulatory maximum retail investor application constraint of Rs. 100,000 rupees per IPO. Column (2) of the table shows the total number of retail investor applications received for each share category, and column (3) is simply the product of columns (1) and (2).

Column (4) shows the investor allocation under a proportional allocation rule, i.e., $\frac{c x}{v}$. The proportional allocation rule would yield $v=37.62$, which is less than the firm's minimum

\footnotetext{
${ }^{14}$ These data are obtained from http://www.chittorgarh.com/ipo/ipo_boa.asp?a=134.
} 
lot size of 150 shares per investor for all share categories. By regulation, the firm is now required to conduct a lottery to decide share allocations.

Column (5) shows the probability of winning the lottery for each share category $c$, which is $p=\frac{c}{v}$. For example, $2.7 \%$ of investors that applied for the minimum lot size of 150 shares will receive this allocation (this is the treatment group in this share category), and the remaining $97.3 \%$ of investors applying in this share category (the control group) will receive no shares. In contrast, $40.6 \%$ of investors in share category $c=15$ receive the minimum lot size $x=150$ shares. For this particular IPO, all retail investors are entered into a lottery, and ultimately receive either zero or 150 shares of the IPO.

Column (6) shows the total number of shares ultimately allotted to investors in each share category, which is the product of $x$, column (2), and column (5). Columns (7) and (8) show the total sizes of the treatment and control groups (number of retail investors) in each share category for the Barak Valley Cements IPO lottery, respectively. Across all share categories, 12,953 investors are treated and 55,669 are in the control group.

It is perhaps easiest to think of our data as comprising a large number of experiments, in which each experiment is a share category within an IPO. Within each experiment the probability of treatment is the same for all applicants, and we exploit this source of randomness, combining all of these experiments together to estimate the average causal effect of winning an IPO lottery on future holdings of the IPO stock. We explain this more fully in the methodology section, following the data description below.

\subsection{Data}

When an individual investor applies to receive shares in an Indian IPO their application is routed through a registrar. In the event of heavy over subscription leading to a randomized allotment of shares, the registrar will, in consultation with one of the stock exchanges, perform the randomization to determine which investors are allocated. We obtain data on the full set of applicants to 85 Indian IPOs over the period from 2007 to 2012 from one of 
India's largest share registrars. 54 of these IPOs had at least one randomized share category. This registrar handled the largest number of IPOs by any one firm in India since 2006, covering roughly a quarter of all IPOs between 2002 and 2012, and roughly a third of all IPOs over our sample period.

For each IPO in our sample, we observe whether or not the applicant was allocated shares, the share category $c$ for which they applied, the geographic location of the applicant by pincode, ${ }^{15}$ the type of bid placed by the applicant (cutoff bid or full demand schedule), the share depository in which the applicant has an account (more on this below), whether the applicant was an employee of the firm, and other application characteristics such as whether the application was supported by a blocked amount at a bank. ${ }^{16}$

Our second major data source allows us to characterize the equity investing behavior of these IPO applicants (and in particular their trading decisions regarding the IPO stock). We obtain these data from a broader sample of information on investor equity portfolios from Central Depository Services Limited (CDSL). Alongside the other major depository, National Securities Depositories Limited (NSDL), CDSL facilitates the regulatory requirement that settlement of all listed shares traded in the stock market must occur in electronic form. CDSL has a significant market share - in terms of total assets tracked, roughly $20 \%$, and in terms of the number of accounts, roughly 40\%, with the remainder in NSDL. While we do also have access to the NSDL data (these data are used extensively and carefully described in Campbell et al., 2014), we are only able to link the CDSL data with the IPO allocation information, as we describe below.

The sensitive nature of these data mean that there are certain limitations on the demographic information provided to us. While we are able to identify monthly stock holdings

\footnotetext{
${ }^{15}$ Pincodes in India are postal codes managed and administered by the Indian Postal Service department of the Government of India. They are similar to zipcodes in the US, although they cover a larger geographical region in India.

${ }^{16}$ An application supported by blocked amount (ASBA) investor is one who has agreed to block the application money in a bank account which will be refunded should she not be allocated the shares in an IPO. The alternative is paying by cheque, i.e., in either case, the money is placed in escrow prior to the allotment process, but in the case of ASBA, any refunds are processed a few days faster.
} 
and transactions records at the account level in all equity securities in CDSL, we have sparse demographic information on the account holders. The information we do have includes the pincode in which the investor is located and the type of investor - accounts are classified as beneficial owners, domestic financial institutions, domestic non-financial institutions, foreign institutions, foreign nationals, government, or retail accounts. This paper studies only the category of retail accounts, as the IPO lottery only applies to this group of investors.

In order to match the application data to the CDSL data on household equity portfolio choice, we obtain a mapping table between the anonymous identification numbers of household accounts from both data sources. We verify the accuracy of the match by checking common geographic information fields provided by both data providers such as state and pincode. $^{17}$

Every applicant for an IPO must register to open (or already have) an account with either of the two depositories (CDSL and NSDL), as the option to receive allocated shares in an IPO in physical form does not exist. For all applicants with accounts in CDSL, we observe accounts that applied for an IPO and were allotted in the lottery, i.e., the treatment group, as well as those that applied, but due to randomized allocation did not get allocated any share in an IPO (the control group).

All CDSL trading accounts are associated with a tax related permanent account number (PAN), and regulation requires that an investor with a given PAN number can only apply once for any given IPO. ${ }^{18}$ Thus no investor account may simultaneously belong to both the control and treatment group, or be allocated twice in the same IPO. However, it is possible that a household with multiple members with different PAN numbers could submit multiple applications for a given IPO in an attempt to increase the household's likelihood

\footnotetext{
${ }^{17}$ We are able to match 99.5 percent of our IPO lottery applicants to our data on portfolio holdings.

${ }^{18}$ In July 2007 it became mandatory that all applicants provide their PAN information in IPO applications. (SEBI circular No.MRD/DoP/Cir-05/2007 came into force on April 27, 2007. Accessed at http://goo.gl/OB61M2 on 19 September 2014.) We confirm there are no violations of this regulation in our data, by checking across all brokerage accounts associated with the anonymized tax identification number of each investor.
} 
of treatment. While we do not directly control for this possibility, we do not believe that this is likely to materially affect our inferences, as we discuss in more detail in the Section covering potential explanations of our results.

Appendix Figure A.7.1 shows the coverage of IPOs in our sample relative to that in the universe of IPOs. Our sample coverage closely tracks aggregate IPO waves, with a severe decline in 2009, and high numbers of IPOs in 2008 and 2010. In our sample of 85 IPOs, 54 IPOs have at least one share category with a randomized lottery allocation, compared to the universe of 176 IPOs with randomized allocations over the period. Appendix Table A.7.1 presents summary statistics on the 54 IPOs with randomized allotments in our sample. The table shows that these IPOs account for $22 \%$ of all IPOs over this period by number, and US\$2.65 BN or roughly $8 \%$ of total IPO value over the period, varying from a low of $0.72 \%$ of total IPO capital in 2009 to a high of roughly $25 \%$ in 2011.

Between $32 \%$ and $35 \%$ of shares in these IPOs are allocated to retail investors who are not employees of the IPO firm. ${ }^{19}$ The average IPO in our sample is 12 times oversubscribed, and we observe a total of 383 randomized share categories (or experiments) across 54 IPOs. These IPOs, and more broadly IPOs in India, under perform in the long run, in a manner consistent with the patterns and trends documented widely in the literature (see Appendix Figure A.7.2). When appropriately adjusted for per-capita GDP differences between the US and India, the account value distribution for the universe of investors in the CDSL data and the lottery sample, are similar to those in the US (see Appendix Figure A.7.3 (a)). While the number of investors who undertake only one trade in the sample is higher in India than in the US, the distribution of trading activity is very similar across the two samples except at the tails (see Appendix Figure A.7.3 (b)).

\footnotetext{
${ }^{19}$ This is slightly below the mandatory $35 \%$ allocation to retail investors because we do not include employees in this calculation as employees are not randomly assigned shares. For further details, refer to the Appendix Section A.1.
} 


\subsection{Using IPO Lotteries to Estimate Endowment Effects}

We estimate endowment effects by comparing the tendency of lottery winners to continue to hold a stock that they were randomly assigned to the tendency of lottery losers to begin to hold a stock they randomly did not receive. It is important to clarify what exactly our lottery winners are endowed with relative to our lottery losers. Table 2 characterizes the application and allotment experience the investors in our analysis received upon being randomly chosen to receive IPO shares. Column (1) of the table shows the mean across all investors in the treatment groups of IPOs in our 383 share category experiments for each of the variables listed in the row headers. ${ }^{20}$ Columns (2) through (6) present the percentile of each variable in terms of the distribution across all of the experiments. ${ }^{21}$

On average, both lottery winners and losers put 1,750 dollars into an escrow account to participate in the lottery (row 1, Table 2). Lottery winners receive an average of 150 dollars worth of the IPO stock in the IPO lottery (row 3). They also receive an instant gain of 62 dollars on average, because IPO stocks' listing price is 39 percent higher than the issue price on average (row 5). Lottery losers cannot purchase the stock at the issue price, so the total endowment that the winners receive (which the losers do not) is 212 dollars $(150+62)$ of the IPO stock. Both winners and losers get refunds from their escrow accounts of approximately 1,600 and 1,750 dollars, respectively. Once the stock has started trading, both winners and losers are free to trade the stock.

Our approach to estimating endowment effects has important similarities as well as some differences with the two major laboratory methods that have been used. The assignment of treatment is similar to the "valuation paradigm" methodology; experiments in this paradigm randomly assign subjects to owning or not owning an object, and then survey the subjects on their valuation of that object. The key result is that sellers typically report higher

\footnotetext{
${ }^{20}$ The means are calculated across share categories using the same weighting scheme implied in our regression based comparison of treatment and control means. See Section 3 for details.

${ }^{21}$ We first calculate the mean within each experiment, and then report the corresponding percentile across the experiments. For example, the median share category experiment had a mean application amount of 792 dollars (first row of Table 2).
} 
valuations than buyers (the so called willingness to accept - willingness to pay or WTAWTP gap). ${ }^{22}$ Our setting parallels this method, in the sense that winners of the IPO lotteries are randomly assigned to own the stock, whereas losers are randomly assigned to not own the stock. This randomization ensures that there should not be preference or belief based reasons why winners should value the stock more than losers. Also similarly to these valuation experiments, winners receive a wealth effect when they are endowed with the IPO stock, since winners are allowed to purchase the IPO stock at the issue price and then sell it at the listing price. ${ }^{23}$ Since it is not possible for the lottery losers to purchase the stock at the issue price, this constitutes a wealth gain (or loss) that is not available to lottery losers. ${ }^{24}$ This literature has typically argued that the wealth effects of assigning a consumer good (typically, a mug or a pen) are small relative to the subject's wealth, and are therefore unlikely to drive their results. Our arguments regarding wealth effects are similar, in that the gains on the lottery shares are most likely small relative to household wealth, and additionally, small relative to the escrow amount that households put in place to participate in the IPO allocation process to begin with. We discuss this issue in more detail in Section 4.

A major difference between our design and experiments in the valuation paradigm is that we infer how subjects value the endowment based on their actual trading decisions, as opposed to surveying investors regarding their valuation of the stock. If there is a large divergence in whether winners or losers hold the stock, this suggests valuation differences across the two groups (assuming negligible wealth and transaction cost effects, which we investigate later). In this sense, our approach is similar to the "exchange paradigm" methodology (see, for example, Engelmann and Hollard (2010)), where laboratory subjects are randomly

\footnotetext{
${ }^{22}$ For a review see Ericson and Fuster (2014), and for early papers using this method see Knetsch and Sinden (1984), Heberlein and Bishop (1986), and Kahneman et al. (1990).

${ }^{23}$ We refer to the first price the IPO stock trades at on the market as the "listing" price.

${ }^{24}$ The wealth gain in our setting is not equal to the total amount of the endowment because our lottery losers receive a refund equal to the amount of the allotted stock (valued at the issue price). The differential wealth gain to winners versus losers is therefore just the gain in the value of the allotted stock based on the listing return of the stock (62 dollars on average, as described above).
} 
assigned good A or good B, and then later asked if they want to trade. The extent to which the holdings depart from equal proportions in groups randomly assigned goods A and B to begin with provides a quantitative estimate of the endowment effect. The logic here is that after getting the opportunity to trade, both groups should contain equal proportions of owners of goods A and B - just as in our setting, winners and losers should contain equal proportions of IPO stockholders.

In addition to being based in a market setting outside the laboratory, our natural experiment design also avoids four specific laboratory features that have been highlighted as spuriously producing endowment effects in Zeiler and Plott (2004): 1) the endowed object is placed physically in front of the subject, and therefore endowed subjects might gain more information about the endowed versus non-endowed object 2) the endowed object is called a "gift" 3) the procedure measuring the willingness to accept and willingness to pay is not properly incentivized, and 4) the subject is not guaranteed anonymity when making choices. In our setting, 1) lottery winners do not have access to any information about the IPO security that lottery losers cannot obtain through publicly available sources; 2) there is little reason to believe winners would frame receiving the IPO stock as a gift given they put down large escrow amounts to apply for the shares and have to pay the issue price; 3) we measure the endowment effect by measuring the actual divergence in holdings of the IPO stock, which investors are clearly incentivized to choose optimally; and 4) the anonymous nature of financial markets makes it unlikely that investors are concerned about others observing their choices.

\section{Documenting the Endowment Effect}

Our empirical analysis begins by documenting the rate of ownership of the endowed IPO stock across our lottery losers and winners over time. We view each randomized share category in each IPO as a separate experiment with a different probability of being allotted 
shares. The idea of our empirical specification is to pool all of these experiments in order to maximize statistical power, while ensuring that we exploit only the randomized variation of winning status within each IPO share category.

For example, one of our tests checks whether lottery winners are more likely than losers to hold the IPO stock at the end of the month in which the IPO was listed on the exchange. To do so, we employ the account holdings at the end of the listing month for all applicants in our 383 share category experiments to construct an indicator for holding the IPO stock at the end of the listing month. We then regress this on a treatment indicator and a fixed effect for each separate experiment. These experiment-level fixed effects ensure that our identification of the treatment effect of winning the lottery stems solely from the random variation in treatment within each experiment. ${ }^{25}$

More generally, we estimate the causal effect of the experience of winning an IPO lottery on various measures of holdings of the IPO stock for each (event) month $t$, by estimating cross-sectional regressions of the form:

$$
y_{i j c}=\alpha+\rho I_{\left\{\text {success }_{i j c}=1\right\}}+\gamma_{j c}+\epsilon_{i j c} .
$$

Here, $y_{i j c}$ is an outcome variable of interest (for instance, an indicator for whether the account holds the IPO stock) for applicant $i$ in IPO $j$, share category $c . I_{\left\{\text {success }_{i j c}=1\right\}}$ is an indicator variable that takes the value of 1 if the applicant was successful in the lottery for IPO $j$ in category $c$ (investor is in the winner group), and 0 otherwise (investor is in the loser group). $\quad \rho$ are the estimated treatment effects in each event-month $t . \quad \gamma_{j c}$ are fixed effects associated with each experiment, i.e., each IPO share category in our sample. Angrist et al. (2013) refers to these experiment-level fixed effects as "risk group" fixed effects. Conditional on the inclusion of these fixed effects, variation in treatment is random, meaning that the

\footnotetext{
${ }^{25}$ See Chapter 3 of Angrist and Pischke (2008) for a discussion of how regression with fixed effects for each experimental group identifies the parameter of interest using only the experimental variation. Our strategy is similar to that employed in Black et al. (2003), who estimate the impact of a worker training program that was randomly assigned within 286 different groups of applicants and Gelber et al. (2015) who study the impact of summer youth employment which is randomized by lotteries within job providers.
} 
inclusion of controls should have no effect on our point estimates of $\rho$. We run this regression separately for different months after the IPO stock is allotted (i.e., we run one of these crosssectional regressions for the month after the IPO was allotted, another for two months after the IPO was allotted, and so on.)

Angrist (1998) shows that our estimated treatment effect $\rho$ is a weighted average of the treatment effects from each separate share category experiment. In particular, the weights are constructed as:

$$
w_{c}=\frac{r_{c}\left(1-r_{c}\right) N_{c}}{\sum_{k=1}^{383} r_{k}\left(1-r_{k}\right) N_{k}}
$$

where $r_{c}$ and $N_{c}$ are the probability of treatment and sample sizes in share category $c$, and we have a total 383 share category experiments. Intuitively, the regression weights give more importance to experiments in which the probability of treatment is closer to $\frac{1}{2}$, and experiments with larger sample sizes - i.e., experiments in which there are many accounts in both treatment and control groups. This weighting scheme implies that our regression estimate exploits purely random variation in treatment induced by the lotteries, since treatment versus control comparisons are only performed within share categories, and since $\rho$ is simply a weighted average of these share-category-specific effects.

Randomization Check. Table 3 presents summary statistics and a randomization check comparing our lottery winner (treatment) and lottery loser (control) groups. Columns (1) and (2) present the means of variables listed in the row headers in treatment and control groups respectively, and Column (3) presents the difference across the two samples with ***, **, and * indicating statistically significant differences at the $1 \%, 5 \%$, and $10 \%$ levels. $^{26}$ All of these variables are measured the month before allotment of the treatment IPO. If the allocation of IPO shares is truly random, we would expect few statistically significant differences across winner and loser groups prior to the assignment of the IPO shares. Column (4) calculates the percent of our 383 share category experiments in which the treatment and

\footnotetext{
${ }^{26}$ These means are calculated using the weights defined in equation (2), which are the same weights that our main estimating equation uses to combine the share category by share category experimental results in to one treatment effect estimate.
} 
control groups were significantly different at the $10 \%$ level. Under the null hypothesis that treatment status is random, we expect that roughly $10 \%$ of these experiments will exhibit a significant difference at the $10 \%$ level.

The first variable we check for balance on is whether accounts that won the current lottery were also more likely to have been successful in receiving IPO shares in the past. If it was possible to "game" the lottery and increase one's probability of winning we would expect current winners to also have been more successful in the past. ${ }^{27}$ Table 3 shows that virtually identical fractions $(38 \%)$ of both treatment and control investors applied to an IPO with our registrar, or were allotted shares in an IPO not covered by our registrar, in the month prior to treatment.

The next few rows of Table 3 present summary statistics on the application characteristics of control and treatment investors. As mentioned earlier, 93\% of these investors submitted an application with a "cutoff" bid, and $4 \%$ used ASBA rather than cheque payment to fund the application. The geographic distribution of investors is concentrated in states with major economic activity, in particular Gujarat, Maharashtra, Rajasthan, and Delhi.

The table shows that $78 \%$ of treatment and control investors had an account value greater than zero in the month prior to the IPO. Portfolio value amounts are highly skewed so we transform this variable using the inverse hyperbolic sine function ${ }^{28}$ - we find that portfolio values, which are on average US\$ 530 including zero values, are not significantly different across treatment and control accounts. The next rows show the fractions of treatment and

\footnotetext{
${ }^{27}$ In the case of IPOs for which our data provider was the registrar, we can directly measure whether or not an account applied to an IPO in each of periods +1 to +6 . For IPOs where our data provider was not the registrar, we can observe whether the account was allotted shares since we see allotments for the entire universe of IPOs from the CDSL data. We set the outcome variable to one in either case - if we see an application for IPOs for which our data provider was the registrar, or if we see an allotment for IPOs not covered by our registrar - and zero otherwise. For the set of IPOs for which we can observe allotments but not applications, our measure is noisy, because although an account had to apply to receive shares, there are also accounts which applied but did not receive shares. We focus on this combined measure because it includes all of the information available to us.

${ }^{28} \sinh ^{-1}(z)=\log \left(z+\left(z^{2}+1\right)^{1 / 2}\right)$. This is a common alternative to the log transformation which has the additional benefit of being defined for the whole real line. The transformation is close to being logarithmic for high values of the $z$ and close to linear for values of $z$ close to zero. See, for example, Burbidge et al. (1988) and Browning et al. (1994).
} 
control accounts that fall into the range of portfolio values described in the row headers. The distribution of portfolio values is roughly U-shaped in both treatment and control accounts, with a relatively large number of accounts with zero value (some of these correspond to new market entrants, or "rookies" as we identify below), and roughly a quarter of the accounts with portfolio values over US\$5,000.

The next set of variables describes the trading behavior of our treatment and control samples. Gross transactions value (calculated as the sum of the value of stocks bought and sold in a month) is roughly US\$ 203 on average including zeros. It is striking that nearly half of the accounts observed traded more than US\$1,000 in the month prior to treatment. Turning next to the total number of buy and sell transactions undertaken in a month, we find that approximately $31 \%$ of accounts made no trades in the month prior to the IPO, and this distribution is also U-shaped. Half of the accounts make between 1 and 10 trades a month. Overall, it appears that the investors in the sample trade substantial amounts, measured either way.

In terms of number of securities in each portfolio, both treatment and control accounts on average hold 9 securities in their portfolio before treatment. In terms of account age at the time of the treatment IPO, approximately $30 \%$ of accounts are less than six months old, $33 \%$ are between 7 and 25 months old, and $37 \%$ are over 25 months old.

Overall, we find that the differences across treatment and control groups are small and typically not statistically significant at standard levels. The fraction of experiments with greater than ten percent significance is around ten percent. Given the similarity of treatment and control groups across this wide set of background characteristics, we confirm that the IPO shares allocated through the lottery mechanism appear to be randomly assigned to investors.

Main Results. Table 4 presents our main estimates. The first column presents statistics as of the end of the first day of trading (Listing Day). The remaining columns show the portfolio behavior observed at the end of each event month following the IPO listing (month 
zero is the listing month). Each row employs a different measure of the holdings of the IPO stock. Within each row header, the first and second rows present the estimated mean of the variable in the treatment and control group from equation 2 respectively and the third row presents the estimated $\hat{\rho}$ from equation 1, i.e., the weighted difference between treatment and control group experimental means.

The first row considers an indicator for whether the account holds any of the IPO stock as the dependent variable. At the end of the first day of trading, we find that approximately 70 percent of lottery winners hold the IPO stock, while only .007 percent of losers hold the IPO stock. The difference is significant at the 1 percent level. One way to interpret this result is that approximately 30 percent of applicants, on average, do not show an endowment effect because their behavior (i.e., not holding the stock at the end of the first day) is consistent regardless of whether they randomly won or lost the lottery. In contrast, 69.3 percent of applicants demonstrate an endowment effect at the end of the first day. ${ }^{29}$

At the end of the listing month (0), lottery winners are 62 percent more likely to hold the IPO stock than lottery losers. This treatment effect declines to 46 percent at the end of six months, with all differences significant at the 1 percent level. The loser group means show that it is relatively rare for lottery losers to own the stock - on average 1 percent of lottery losers own the IPO stock in the month in which it lists, this number only rises to 1.6 percent six months post-listing.

The second row header defines the dependent variable as the fraction of the potential IPO allotment that the account holds. For example, if winners in a particular share category lottery won ten shares and a given account holds five shares, the dependent variable would be defined as 0.5. For lottery losers this variable is also defined as the number of shares of the IPO stock they hold divided by the allotment they would have received had they won the lottery. For example if winners won ten shares, then a loser account that chose to

\footnotetext{
${ }^{29}$ We only present the first day results for the indicator for holding the IPO stock (I(Holds IPO Stock)) because this variable is the most reliably estimated given our data (we only observe monthly holdings data, so we have to make some assumptions to determine whether an account held the IPO stock at the end of the listing day). Appendix A.6 provides details on variable construction.
} 
purchase five shares on the market would have this measure equal to 0.5. For this measure, the treatment effect is slightly smaller at the end of month 1 , but otherwise very similar to the first row. However, a comparison of lottery loser means across the first and second variables reveals that conditional on holding the IPO stock, lottery losers choose to hold a substantially larger fraction than the lottery allotment. In particular, Column (1) for month 0 shows that one percent of the lottery losers hold the stock, but their average fraction of allotment is 4.4 percent, implying that lottery losers who choose to own the stock purchase roughly four and a half times the amount of lottery allotment. ${ }^{30}$

The third row is an indicator for whether the account holds exactly the number of shares allotted to winners in the relevant share category. Results here are similar to those in the first row, suggesting that most of the divergence between winners and losers arises from lottery winners continuing to hold initial allotments, while losers are unlikely to purchase the exact allotment they did not receive in the lottery.

The fourth shows the US\$ value of the IPO stock held in the portfolio at the end of the month. Lottery winners hold US\$108 more of the stock than losers on average at the end of the first month, US\$ 84 more at the end of the second month, and US\$ 55 more at the end of the sixth month. This measure includes differences in chosen holdings between winners and losers as well as returns earned on those shares, meaning that some of the decline in this measure is attributable to significant negative returns on these IPO stocks on average, as we describe below. The fifth row shows the weight of IPO stock in the investor's portfolio, and shows that lottery winners hold 13 percent more of their portfolio in the IPO stock in month 0 , which remains substantially higher at 6 percent six months after allotment.

The final rows of the table show average percentage returns to holding the IPO stock to the end of each month. On average the listing return (i.e., the percentage return lottery winners gain over the issue price as soon as the stock begins trading) is 42 percent. The next

\footnotetext{
${ }^{30}$ Suppose there are 10,000 lottery losers, the lottery allotment (to winners) was 10 shares, and 100 losers purchase the stock (1 percent). Also suppose that those 100 losers choose to purchase 50 shares. Then, the average fraction of the allotment held by lottery losers will be 5 percent $(.01 * 5+.99 * 0=.05)$.
} 
two rows show cumulative returns from holding the stock assuming that the stock was (1) won in the lottery, or (2) purchased at the first trading price. The weights used to calculate these average returns are the same as those in equation 2, i.e., these return estimates combine information across experiments in the same way as in the estimated treatment effects.

The returns data show that lottery winners on average lost money based on their choice to continue to hold the stock after it was initially listed, since returns relative to the first trading price are large and negative. In this sense, lottery losers in our sample make a relatively good decision (on average) to not purchase these IPO stocks at the first trading price. Clearly, what constitutes a good decision depends on the realization of returns in any particular sample, but the key result is that the two groups chose to make substantially different decisions about holding the stock. ${ }^{31}$

Table 5 extends the analysis to 24 months after the lottery. ${ }^{32}$ We find that even 24 months after allotment, lottery winners are 36 percent more likely to hold the IPO stock than the lottery losers. However, lottery losers' propensity to hold the stock stays relatively constant, at around 1.5 to 1.7 percent over these 24 months.

The Relationship Between the Endowment Effect and Experience. We document how the differential holding patterns of the IPO stock vary with plausible proxies of investors' experience in the IPO market. To do so, we interact our main treatment variable in equation 1 with a set of predetermined variables that we believe are interesting proxies for the amount of experience in the IPO market, in a descriptive, non-causal analysis, similar to the analysis in List (2003). Table 6 presents the results.

Column (1) in Table 6 takes equation (1), and adds a set of interactions between the treat-

\footnotetext{
${ }^{31}$ For example, if this pattern of negative post-issue returns is predictable, then we would expect both lottery winners and losers to choose not to hold the stock after listing; it would not be very difficult for lottery winners to have a decision rule where they always sell the stock after it lists, and a simple decision rule like this would eliminate the divergence in behavior. Instead, however, we see a strong divergence in behavior across the groups.

${ }^{32}$ The results for periods one and four months after IPO listing are slightly different from those in Table 4 because we restrict this analysis to those IPOs where we can observe the portfolios of lottery winners and losers at least 24 months after the IPO allotment (i.e. given our portfolio holdings data ends in March 2012 we only include IPOs that occurred in or before March 2010 here). The results for this sample are similar to the results for the full sample in Table 4 in month 1, and the trend is similar through month 8 .
} 
ment dummy and various continuous proxies of investors' experience, listed in the rows. ${ }^{33}$ Column (2) adds portfolio size and age of the investor account as additional controls to Column (1). Columns (3) and (4) replace these linear interactions with interactions with dummy variables based on tercile or quartile breakpoints of the respective variables. Our discussion below mainly focuses on Column (4). ${ }^{34}$

The first set of rows shows that the estimated endowment effect is highly correlated with the number of IPOs that the winner had been allotted in the past. Accounts which received over 8 (random and nonrandom) allotments in the past have estimated endowment effects that are 17 percentage points smaller than investors with no past IPO experience. However, relative to the base rate listed in the very first row (77.9 percent), even such "experienced" IPO allottees are 60 percent more likely to hold the IPO stock at the end of the first month.

Similarly, the next set of rows show that experience measured by trading activity also reduces the observed endowment effect. Winners with more than 6 trades in the month before IPO allotment are 14.3 percent less likely to hold the IPO stock compared to those with no past trades. Moreover, high numbers of trades are also associated with greater buying activity by lottery losers.

Finally, we measure past return experience by constructing the fraction of realized returns in the preceding six months to the IPO allotment that is greater than the listing return observed in the treatment IPO. We find that if the IPO returns are substantially greater than most previously experienced returns, the endowment effect reduces considerably. Interestingly, the reverse seems to be true for the control group - they appear to have a higher propensity to hold IPOs which have higher listing returns than most they have ever experienced, and vice versa.

Figure 1 (c) suggests that some version of the disposition effect may be in operation

\footnotetext{
${ }^{33}$ We define all independent variables in this regression in the month prior to the lottery allotment to avoid mechanical correlations between the dependent and independent variables due to the lottery allotment.

${ }^{34}$ Note that the reason that the addition of the portfolio and age controls in Columns (2) and (4) changes the winner treatment effect is because this specification includes winner interactions with a set of pre-existing variable.
} 
for lottery winners, and this finding on the role of the past return experiences of lottery winners and losers in explaining their propensity to hold or buy suggests a link between the observed disposition effect and personal experience. These results are also consistent with our previous evidence that wealth effects are unlikely to be driving the endowment effects in our setting (we would expect the effects to get smaller as these returns increase if wealth effects were driving the result).

Overall, these results suggest that there is a correlation between measures of investor experience and smaller endowment effects, consistent with the findings in List (2003). However, having experienced many allotments in the past does not appear to lead to quick and complete elimination of the endowment anomaly in this setting.

The above analysis focused on testing whether the divergence between lottery winners and losers varies based on the total number of IPO lotteries experienced. The advantage of that approach is we have several holistic measure of an investors' total experience in the market. However, it is also possible to estimate the shorter run relationship between experience and endowment effects by testing whether winners in a recent lottery show lower endowment effects in a current lottery. We leave the details of this analysis to the Appendix Section A.4, but note here that while the effects of winning on future endowments is indeed negative, the effect size is small, suggesting that it would take significant numbers of such experiences to reduce the observed endowment effect. ${ }^{35}$

The Relationship Between the Endowment Effect and Listing Returns. Figure 1 presents the fraction of the IPO allotment that lottery winners and losers choose to hold of the IPO stock at different time intervals, plotted against the returns accruing on the IPO

\footnotetext{
${ }^{35}$ It is important to note that there are two potential mechanisms underlying these negative estimates. The first is that winning shares in an IPO causes a given account to exhibit the endowment effect less in a future IPO (i.e. a causal effect of experience). The second is that the types of players who choose to apply to the second IPO after winning shares in the first are differentially selected to be the type who have lower endowment effects (i.e. a selection effect). Previous studies, such as List (2011), focus on separating these two effects, but this is difficult in our setting as the choice to apply for a future IPO is endogenous. However, in this particular analysis the joint effect is a primary object of interest; it tells us whether the two forces of investors learning from experience as well as the force of experiences driving some investors out of the market, lead to lower market anomalies (such as the endowment effect) over time.
} 
stock over that interval. These relationships are particularly useful in testing the theories discussed in the next section.

Figures $1 \mathrm{a}$ and $1 \mathrm{~b}$ plot the fraction of the allotment of the IPO stock held at the end of the listing day on the y-axis. Figure 1a plots this measure against the percentage listing return on the $\mathrm{x}$-axis, while Figure $1 \mathrm{~b}$ uses instead the dollar value of the listing gain on the $\mathrm{x}$-axis.

Figures 1c and 1d plot the fraction of the allotment of the IPO stock held at the end of the first month post-listing on the y-axis. Figure 1c has on the x-axis the percentage return on the stock to the end of the first month, and Figure 1d replaces this with the change in the dollar value of the IPO allotment over the same interval on the x-axis.

Figures $1 \mathrm{a}$ and $1 \mathrm{~b}$ show that the endowment effect (the average difference between the winners and losers fraction of allotment held) has little relationship with the listing gain. Figures $1 \mathrm{c}$ and $1 \mathrm{~d}$ show that the size of the endowment effect falls sharply with the experienced return on the stock in the month after listing, reminiscent of the disposition effect. We later discuss these results as they relate to the predictions of the theoretical models that we consider.

Effect Size Comparison. Appendix Table A.7.3 compares the endowment effect sizes we estimate to those found in recent field studies. Each experiment we report here randomly assigned a good $a$ and good $b$ to participants and then gave them the opportunity to trade for the other good. We define the endowment effect for each study to be the fraction of those endowed with good $a$ who choose to keep it minus the fraction of those endowed with $b$ who choose to trade for $a$.

We find that our low experience sample (defined as either having zero, 1, or 2 previous IPO allotments) has similar endowment effect sizes as the range of effects found amongst the low experience samples in List (2003) and List (2011), despite the very different context (Panel A). Turning to our sample of highly experienced investors, however, we find endowment effects substantially larger than those found amongst the high experience samples in previous 
field experiments. While it is of course difficult to pinpoint why our effects are larger even for the most experienced subjects, our finding does raise the possibility that experience does not eliminate the endowment anomaly in important field settings.

Overall, our analysis of the relationship between experiences and estimated endowment effects suggests that 1) investors with greater experience exhibit lower endowment effects (due to either a causal effect of experience or selection), and 2) that it is unlikely that experience quickly and absolutely eliminates the endowment anomaly.

Next, we turn to evaluating explanations for our results. We begin by considering a series of explanations that assume that individuals have preferences and beliefs within the standard expected utility maximization framework, but some other feature of the setting causes those endowed to prefer greater holdings of the asset. We then turn to evaluating a set of models which involve non-standard preference specifications or non-standard belief formation. While we describe the intuition behind various models below, we leave the solutions of these models and a more formal presentation to Appendix Section B.

\section{Standard Expected Utility Explanations}

Transactions Costs, Wealth Effects, and Taxes. We consider the extent to which wealth effects, monetary transactions costs such as brokerage commissions, disincentives for flipping (i.e., investors might believe they will be penalized in future IPOs if they flip the stock), and tax motivated behavior are possible explanations for our estimated endowment effects. ${ }^{36}$ Overall, we find little evidence to suggest these play an important role. We provide the results of specific tests of each of these additional explanations in Appendix A.5.

Simple Substitution Effects. One possibility is that investors who lose the IPO lottery decide to buy a substitute stock (i.e., a stock to take the place of the IPO stock that they lost in the lottery, which they were unable to secure at the issue price). This behavior could

\footnotetext{
${ }^{36}$ Our discussion of wealth effects also includes the possibility of a "house money effect" explaining our results, as both are unlikely to explain our results for similar reasons. See appendix for details.
} 
potentially generate an endowment effect; lottery winners would tend to hold the IPO stock because winning that IPO satisfied their demand, and lottery losers would own a different stock (with potentially similar characteristics). If this were a common phenomenon it would reduce the economic magnitude of the endowment effect broadly construed, as if we defined the losers' comparison holdings more broadly (for example as any stock in the same industry as the IPO stock) we might find small differences across lottery winners and losers.

Contrary to this hypothesis, however, we find that at the end of the month after the IPO stock lists the lottery winners hold almost exactly one additional stock relative to the lottery losers. This means that lottery losers are not buying different stocks to close the gap in the number stocks of held (Appendix Figure E.4). Moving forward in time in Appendix Figure E.4, we also see that the trends in the lottery winner and loser groups are almost exactly parallel, once again suggesting that the lottery losers do not make differential purchases in substitute shares. Finally, in Anagol et al. (2015) we find that lottery winners are actually 5 to 7 percentage points more likely to buy non-IPO stocks than lottery losers. If lottery losers were substituting their lottery loss with other shares, we should observe lottery losers being more likely to buy non-IPO stocks in the future. Taken together, these results suggest that lottery losers are staying out of the IPO stock as well as staying out of other shares, and that lottery winners are holding substantially more shares as a result of the randomized endowment.

Inertia at the Portfolio Level. While many economic models assume that investors constantly monitor and adapt their portfolios to changes in information and returns, substantial evidence exists that in practice investors are much slower to respond, and instead are better characterized as being inertial or following the "path of least resistance" (Baker et al., 2007; Mitchell et al., 2006; Madrian and Shea, 2001). Given that our main results (that lottery winners tend to hold the stock while losers do not) comes from inaction on the part of investors in the IPO stock, inertia is naturally a good description of their behavior. In this section we are interested in evaluating whether this inertial behavior is specific to the 
IPO stock, or whether it is driven by inertial behavior at the portfolio level as a whole. If our results are due to the fact that investors are not making any transactions in their entire portfolios, then this obviously would reduce the relevance of our study to other settings where endowment effects may be present. However, if the inertial behavior is specific to the IPO stock, it is interesting to evaluate different theoretical models that could generate the endowment effects observed in the IPO stock (which we turn to in the next Section).

Perhaps the most natural way to conceive of inertia at the portfolio level is that there are substantial costs to making transactions, leading to investors optimally choosing to remain inactive. Such costs would naturally generate an endowment effect, since lottery winners and losers remain at the status quo (winners hold, and losers never buy) as neither group alters their portfolios in the future. Examples of such costs (other than standard monetary transactions costs and taxes, discussed above) might include include "irritation costs" (e.g. lost passwords or account numbers), as well as procrastination arising from a high opportunity cost of time.

A key prediction if such costs are responsible for our results is that the observed endowment effect should be much smaller for accounts that we observe making trades in other stocks aside from the IPO stock in question. If an investor makes a buy or sell trade in another stock, it seems difficult to argue that they could not overcome the forces preventing a trade on the IPO stock, as the marginal cost of putting in a trade on the IPO stock in addition to trades on other stocks is low. Appendix Table A.7.2 shows estimated endowment effects for lottery winners and losers conditional on the number of trades made in non-IPO stocks, and finds a substantial endowment effect even for investors who made more than 20 trades in non-IPO stocks in the same month.

An additional, related, possibility is that winners do not trade the IPO allocation because it might be smaller than the investor's other positions, i.e., the investor may find it worthwhile to pay costs to trade in stocks where he or she has a larger position, but not those in which they have relatively smaller positions. We test this variant by estimating the endowment 
effect for accounts that, in the month prior to winning or losing an IPO allotment, had an average value of buy or sell transactions that was less than the value of the allotment, or make trades in a position size that is less than or equal to the IPO allotment value.

For example, suppose IPO A allotted lottery winners 150 dollars worth of shares. In this case, we check the prevalence of the endowment effect in each month for investors in IPO A that had an average value of purchases less than 150 dollars and made at least one purchase, an average value of sales less than 150 dollars and made at least one sale, or met both these criteria. ${ }^{37}$ We also check the prevalence of the endowment effect for investors who made any transactions in other stocks in their portfolios worth less than or equal to 150 dollars.

Table 7 presents the results. We find that lottery winners in this sub-sample are 58 percent (or 51 percent for the position-size measure) more likely to hold the IPO allocation at the end of the allotment month relative to lottery losers, significant at the 1 percent level. This result is approximately four percentage points (and statistically different from), our result in the full sample of 62.4 percent, which is consistent with the idea that investors who make these small trades have a slightly smaller endowment effect. However, these results are not consistent with the idea that our full sample results are mainly due to most investors ignoring these small transactions, as we find very large endowment effects for even those investors who have recently made a "small" transaction. These accounts also show large endowment effects as we move through time after the allotment. Overall, these results do not appear to support a model where substantial costs of initiating a transaction, combined with the small value of the IPO allotment, are the main drivers of the effects.

Finally, in related work we find that lottery winners are more likely to trade non-IPO stocks in their portfolio than lottery losers, suggesting that, if anything, winning the lottery reduces the transactions costs associated with making a trade (Anagol et al., 2015). This result also goes against the idea that portfolio-level inertia is responsible for our results.

Taken together, the results above suggest that our finding of endowment effects in this

\footnotetext{
${ }^{37}$ We need to require that the account had least one purchase, otherwise an account with no activity would be defined as an account that made a "small trade".
} 
setting are driven by a very specific type of inertia that holds in the IPO stock, but not in the whole portfolio. In the next Section, we present and empirically test economic models that can generate inertia specifically in the IPO stock in our setting.

Information Acquisition Costs and Incentives. Van Nieuwerburgh and Veldkamp (2010) present a model where investors' decisions to learn about assets are jointly determined with their choices to hold those assets. In particular, the mechanism in their model is that investors choose to invest in information about securities they expect to hold; once they have acquired information about the stock it becomes optimal to hold more of the stock, and then once they hold more of the stock it is optimal to invest more in learning about it (because a given information signal is more valuable if the investor owns more shares).

In our setting, both lottery winners and losers should have the same expectations of holding the stock before the randomized allotment is made, so their incentives to learn about the stock should be the same before the allotment is made. Therefore, at the time of allotment, winners and losers should be balanced in the amount of information they have about the IPO stock. However, once winners are endowed with the stock, the model predicts that their incentive to acquire additional information about the IPO stock should be higher, which might be an explanation for the divergence that we observe. ${ }^{38}$ On the other hand, one important feature of our results runs contrary to this explanation for our observed endowment effect. Lottery winners continue to hold the IPO stock even though it produces negative 33 percent returns on average, 6 months after issuance, and negative 62 percent, 24 months after issuance. In other words, if lottery winners are acquiring more information about the IPO stock, they appear to be acquiring particularly poor quality information that is causing them to hold an underperforming asset.

Multiple Applications Per Household. As discussed earlier, households may have an incentive to submit multiple applications through different brokerage accounts to increase

\footnotetext{
${ }^{38}$ Note that for this explanation to apply, it must be the case that there are some transactions costs associated with purchasing the IPO stock; if there are no transactions costs then the lottery losers could costlessly acquire the IPO stock and therefore have roughly the same incentives (modulo the listing gain, which they cannot access) to acquire information about it.
} 
their probability of winning. Could this behavior explain the endowment effect? First, it is not obvious that submitting multiple applications is a good strategy as only approximately one-third of IPOs end up being over-subscribed enough to warrant lotteries. By submitting multiple applications with the intention of only holding the ones that are allocated households would take on the substantial risk of all of their accounts getting allotted. Note also that this behavior would have to be common in almost every IPO share category in our dataset, as the endowment on the listing day is large in almost all share categories (See Figure 1a and $1 \mathrm{~b}$ ), and since some of these share categories had quite large probabilities of allotment (see Table 2). Nevertheless, we explore this further in the appendix, and find other features of this explanation appear strongly inconsistent with our results. ${ }^{39}$

\section{$5 \quad$ Non-Standard Explanations}

In this Section we consider a series of theoretical models that have either been prominent explanations of endowment effects or of investor behavior related to our results (such as the disposition effect) in past work. We aim to determine 1) to what extent these models can generate an endowment effect when set up and solved in environments approximating our real-world setting, and 2) derive additional testable predictions to see whether they hold up in the data. Our goal here is not to conclusively determine which model explains all of our empirical facts, but instead to provide guidance for future empirical work that tests theoretical mechanisms that might drive endowment effects in the field.

1. Expectations Based Reference Dependent Loss Averse Preferences. While a number of potential causes of endowment effects have been studied, the most prominent is based on the idea of reference dependent preferences with loss aversion first proposed in Kahneman and Tversky (1979). A key challenge for this model is the determination of the appropriate psychological reference point around which agents are loss averse. As

\footnotetext{
${ }^{39}$ For example, because the randomization is orthogonal to households' application behavior, this explanation would predict there should be a large amount of buying amongst households where all of the accounts were not allocated - we do not observe this in the data.
} 
different reference points yield different predictions in this (and other) settings, we analyze the implications of a number of different theoretical formulations of the reference point.

Expectations as Reference Points - Constant Prices: Kőszegi and Rabin (2006) present a theory where recently formed expectations about future outcomes determine an agent's reference points. In the case of exchange experiments (i.e., those in which subjects are randomly endowed with good $\mathrm{A}$ or $\mathrm{B}$, and then asked if they would like to trade), one simple prediction is that subjects might expect to be forced to leave with the good with which they were just endowed, and so ownership of the good is the relevant recently-formed reference point. Relative to this reference point, the option of trading the good away is encoded as a loss, and subjects thus tend to hold endowed objects more than would be predicted by standard expected utility preferences.

Ericson and Fuster (2011) set up and solve a model which provides them with theoretical guidance for a laboratory experiment which considers endowments of mugs and pens. We essentially relabel the mug and pen in their model as the IPO stock and cash, and present the conditions necessary to predict an endowment effect in this model (see appendix for details). To do so, we assume that the price of the stock does not vary post-listing, and apply the model formulating the reference point as agents' either expecting to own the stock, or expecting to hold cash equivalent to the stock price (depending on agents' individual preferences for cash vs stock). ${ }^{40}$

The key parameter in this model is $b$, the probability the agent assumes they will be allowed to trade the endowed stock for cash. In laboratory settings, $b$ can be experimentally varied, but in field settings, agents will have their own expectations about whether the economic environment will permit trading of the endowed object. An important testable prediction of this model is that the extent to which the endowment shapes the reference point depends on subjects' expectations of $b$ (Ericson and Fuster, 2014). The model shows that the predicted endowment effect gets weaker as the probability that agents expect to be

\footnotetext{
${ }^{40}$ Note this assumes that investors narrowly frame their decisions about the IPO stock, i.e., they do not combine potential outcomes with the other risky assets that they hold.
} 
able to trade $(b)$ increases; in the limit, when $b=1$, there is no endowment effect.

In our stock market setting, we argue that investors likely believe $b=1$ (or at least, that $b$ is very close to 1) given that stocks are traded on the exchange daily. If so, this model cannot explain our findings. Our results are therefore interesting in light of three recent laboratory studies Ericson and Fuster (2011); Heffetz and List (2014); Goette et al. (2014) that have experimentally varied $b$, and find conflicting evidence on whether endowment effects are eliminated when subjects fully expect to be able to trade in the future (i.e., $b=1$ ). Our results suggest, at a minimum, that endowment effects are possible in markets outside the lab even when agents fully expect to have the opportunity to trade the endowed objects in the future.

Expectations as Reference Points - Expected Distribution of Prices. Within the Köszegi and Rabin (2006) framework, an alternative potential reference point agents might have is ownership of the stock evaluated using the expected distribution of future prices of the IPO stock, rather than a constant future price. Interestingly, the expectations based reference point theory of Kőszegi and Rabin (2006) predicts that decision makers will be less risk averse when the reference point is stochastic and face the choice of a constant alternative (i.e., IPO lottery winners under this more sophisticated formulation), and more risk averse when the reference point is fixed and they face the choice of a stochastic alternative (i.e., IPO lottery losers - assuming that they consider their reference point as holding cash). The fact that lottery winners take greater risk by continuing to hold the IPO stock, while lottery losers choose not to purchase the IPO stock appears consistent with this prediction of the model, under this formulation of reference points. ${ }^{41}$

In the appendix we present a model where lottery participants have expectations based stochastic reference points. In the model, reference points are determined by expectations, which in turn are determined by the lottery participant's plan of action (which is chosen

\footnotetext{
${ }^{41}$ Sprenger (2015) and Song (2015) both present laboratory evidence confirming this prediction of the KR theory. Note that neither standard expected utility theory nor disappointment aversion (another leading theory of reference point determination where the reference point is based on the certainty equivalent of a gamble), predict this so called "endowment effect for risk."
} 
prior to the stock listing). Lottery losers consider two possible plans; one where they do not buy the IPO stock after it lists, and one where they do buy the stock. Similarly, lottery winners consider a plan to sell the stock versus a plan to hold the stock. We are particularly interested in deriving the conditions necessary for an endowment effect to appear: the same agent should want to stick to the plan of holding the stock if they win the lottery, but simultaneously want to stick to the plan of not holding the stock if they lose the lottery.

We find that the model can generate an endowment effect, in the sense that there is a range of probabilities regarding the future success of the stock for which the "endowment effect plan" to hold stock if the agent wins and not buy the stock if the agent loses the lottery is a "personal equilibrium" (PE) in the language of Köszegi and Rabin (2006). The main intuition for this result is the same as in Sprenger (2015), i.e., that agents demonstrate an "endowment effect for risk" - they exhibit lower risk aversion when endowed with a gamble and consider trading it for cash, than when they are endowed with cash and consider trading it for a gamble. The range of probabilities of $q$ that can deliver this effect, however, are limited - in an example calculation from our model in the appendix (assuming the stock can go up or down a fixed amount with probability $q$ ), the agent will demonstrate an endowment effect if $0.4<q<0.6$. In particular, the probability of the up state has to be high enough so that the agent sticks to holding the stock when they win, but simultaneously has to be low enough so that the agent also sticks to the cash if they lose the lottery.

The PE condition satisfied by these parameter values only guarantees that the agent does not wish to deviate from the endowment effect plan. However, it does not guarantee that pursuing this plan delivers the agent the highest expected utility of all possible plans. When we derive these conditions (for a "preferred personal equilibrium" or PPE Köszegi and Rabin (2006)), we find that there is no value of $q$ that can make the the endowment effect plan a PPE. The intuition for the result is that planning to buy the stock and then following through on it (as a lottery loser) delivers exactly the same payoff as planning to hold the stock and following through on it (as a lottery winner). Similarly, planning not to buy the 
stock and following through on it as a lottery loser gives the same payoffs as planning to sell the stock and following through on this plan as a lottery winner. Given this symmetry of payoffs, the model cannot generate losers who get higher expected utility from staying out while simultaneously getting winners to get higher expected utility from staying in the stock.

Thus, while it is possible that this model can generate the endowment effect, it would require us to assume that investors are consistently not choosing their highest expected utility plans. Given this we believe that it is unlikely that this framework is the sole explanation for the endowment effect in our context.

Expectations as Reference Points - Model Including Lottery and the IPO After Market. The reference dependent models presented so far abstract away from the fact that the random assignment in our empirical setting occurs in lotteries with different probabilities of winning, and in IPOs with different listing gains. In Appendix B, we present a model of an agent with expectations based reference dependent preferences who has chosen to enter the lottery for an IPO stock, experiences a listing gain, and decides on a plan of action based on whether or not she wins the lottery, as well as on how the stock performs in the aftermarket. This model is a more realistic characterization of our empirical setting. ${ }^{42}$

In the model, an agent enters an IPO lottery, and wins (loses) with probability $p(1-p)$ and receives (does not receive) the stock. After the agent learns whether or not she won the stock, the stock lists on the exchange at a price greater than the price paid for the stock (i.e., there is a listing gain). Following realization of the listing gain, the investor chooses whether to hold or sell the stock if she wins the lottery, and whether or not to purchase the stock if she loses the lottery. Finally, after this choice is made, the stock either goes up with probability $q$, or down with probability $1-q$.

We analyze the model exactly as suggested by Köszegi and Rabin (2006). Before the lottery results are announced, the agent considers three possible plans of action. The first,

\footnotetext{
${ }^{42}$ We refer the reader to Appendix B for the details of the model, but focus on presenting the basic setup and the intuition for our results in the paper.
} 
we which term the "never hold" plan, is to sell the stock immediately if she wins, and not buy the stock if she loses. The second plan ("always hold"), is to hold the stock if she wins and buy if she loses the lottery. If the agent follows through on either of these first two plans then there is no endowment effect, because the agent has the same position in the stock at the end of the model regardless of whether they were randomly assigned the stock in the lottery. The third "endowment effect" plan is to hold the stock if she wins, but not purchase the stock if she loses the lottery. ${ }^{43}$

In the model, the agent's decisions affect her utility in two ways. First, her choices affect her consumption directly (i.e., by the amount of the value of the stock or cash held at the end of the model). Second, the agent feels gain-loss utility when comparing her actual outcome to her expectations-based reference point. For example, she might experience a utility gain from comparing an outcome of winning the lottery and holding a stock which goes up to losing the lottery and buying a stock which goes down.

Our goal in analyzing the model is to determine the conditions under which the agent does not deviate from the endowment effect plan to either the always hold plan or the never hold plan. ${ }^{44}$ When we solve the model, we find that the expectations based reference dependent framework can generate an endowment effect in this setting. It is worth considering the forces in the model that makes an agent choose the endowment effect plan. The first force is the direct consumption benefit arising from the stock's after-listing performance. These direct consumption benefits alone will never move an agent towards the endowment effect plan - if she expects the stock will do well in the aftermarket, this moves her towards the always hold plan, and if she expects the stock to do poorly, this moves her towards the never hold plan. This means that the reference-dependent gain-loss utility piece (which is the non-standard part of this utility formulation) is what pushes the agent towards the

\footnotetext{
${ }^{43}$ There is a fourth possible plan, where the agent chooses to sell the stock if she wins the lottery but purchase the stock if she loses the lottery. Given that this plan is not empirically relevant, we omit it from our discussion here.

${ }^{44}$ This is the condition necessary to guarantee that sticking to the endowment effect plan is a personal equilibrium (PE).
} 
endowment effect plan.

While we leave the details of the full derivation to the Appendix, we focus here on one derived condition that is easily tested in our data. The condition shows that as the probability that the agent wins the lottery $(p)$ goes to one, that the endowment effect can only be generated for a stock with an expected return very close to zero. The intuition for this result is that the endowment effect in this model is driven by the agent comparing how she feels when she wins the lottery to how she feels when she loses; however, as $p$ goes to one this comparison becomes less and less important because the agent's reference points are less and less affected by her expectations of losing the lottery (since $1-p$ goes to zero). When $p$ is close to one the agent's decisions are essentially determined by the expected return on the stock. If this is positive she will prefer the always hold plan, and if negative, she prefers the never hold plan.

Looking at our empirical estimates of how the endowment effect varies with the probability of winning a given lottery (Table 5), we find that when $p$ goes from zero to one, the endowment effect only goes down from 0.78 to 0.74 . It is true that that the estimated endowment effect gets smaller as the probability of winning is consistent with this model, but it seems implausible that 74 percent of lottery applicants believe that the return on the IPO stock is in a very narrow range around zero. For example, such beliefs are very different from the observed empirical distribution of IPO returns over our sample period - only 1.8 percent of our sample IPOs had returns between zero and one percent over six months.

To summarize, while this model can generate endowment effects, the data do not support the important prediction that the endowment effect should be strongly influenced by the agent's expected probability of winning the lottery.

2. Issue Price as a Reference Price (Weaver-Frederick Model). Another candidate explanation for endowment effects in general (including those in our setting) is that lottery losers have an "aversion to bad deals" as described in Weaver and Frederick (2012); in particular, lottery losers might see purchasing the stock after the IPO as a "bad" deal 
because the stock typically trades higher than the issue price (even though the issue price is irrelevant for the future performance of the stock). We formally apply the model of Weaver and Frederick (2012) to our setting in the appendix, but simply summarize the main results of the model here.

The model can generate an endowment effect because lottery losers' valuations of the stock are distorted downwards due to their disutility from having to pay a price higher than the issue price. However, this distortion does not occur for lottery winners because they already own the stock, and therefore do not have to transact at the listing price to add it to their portfolio.

In addition to predicting an endowment effect, the model also predicts that the endowment effect should get smaller as the listing gain gets smaller. The intuition for this result is that as the listing gain gets smaller, lottery losers have the opportunity to buy the stock at a price closer and closer to the price that lottery winners paid. The motivation for lottery losers to feel like they are getting a "bad deal" when they purchase the stock in the aftermarket therefore declines as the listing gain decreases.

Contrary to this prediction, however, we find in Figure 1 Panels (a) and (b) that there is little evidence of a relationship between the size of the listing gain and the endowment effect. While we cannot be sure to what extent this model helps explain the endowment effect when the listing gain is large, the fact that the effect is so strong for small listing gains suggests that this model is insufficient on its own as an explanation of our results.

3. Realization Utility Model with Loss Aversion: In the appendix, we present a model where the investor gets utility from realized gains and losses relative to the purchase price, i.e., utility from trading in the stock market comes not from future consumption or wealth levels, but instead in the instant the stock is sold. We are motivated to apply this model to our setting because realization utility with loss aversion is the leading theoretical explanation of the disposition effect (Shefrin and Statman (1985), and Barberis (2013)), and we clearly observe disposition-effect type behavior amongst lottery winners in how they 
trade the IPO stock in the aftermarket - winners are more likely to sell IPO stocks that have gained versus lost value as can be seen in Figure 1c and $1 \mathrm{~d} .{ }^{45}$ Our primary question of interest is whether a realization utility model with loss aversion can also explain the fact that lottery winners are so much more likely to hold the IPO stock than lottery losers (i.e., the endowment effect).

In this model, lottery winners choose whether to sell or hold the stock after the listing gain is realized. The key feature is that lottery winners' realization utility is based on the comparison of the listing price (the price they can sell at on the first day) with the issue price (i.e., the issue price is the reference point). We find that this model can generate an endowment effect, but it additionally predicts that the endowment effect should go to zero as the listing gain goes to zero (this prediction is shared with the Weaver-Frederick model). Below, we explain the intuition for this result, considering the cases of small and large positive listing gains, and refer the reader to the appendix for analysis of the negative listing gain cases (which are intuitively similar).

First, consider the case where the listing gain is so large that regardless of the stock's future performance, the lottery winner will always be able to sell at a gain relative to the issue price. In this case, the lottery winner will be in the gain domain regardless of whether he sells right after listing, or chooses instead to hold. However, if the lottery loser were to buy the stock at the listing price, there is the chance that the stock will go down, meaning that he will be in the loss domain. Because the loser has the chance to end up in the loss domain (but the winner does not), he must expect a higher post-listing return on the stock to be willing to hold it, meaning that lottery losers will be less likely to hold the stock in general. As a result, the model predicts an endowment effect in this case.

\footnotetext{
${ }^{45}$ There is an active debate in the literature regarding to what extent the realization utility model can explain the disposition effect as well as other features of the relationship between past returns and individual investor selling behavior. Ben-David and Hirshleifer (2012) consider the extent to which realization utility can explain the relationship between past returns and selling behavior. While the basic empirical pattern of investors who hold the stock selling more as returns increase is similar in our setting to theirs, we also observe the universe of counterfactuals (lottery losers), meaning that the endowment effect also needs to be explained in our setting.
} 
Next, consider the case where the listing gain is small and positive, such that there is a chance that a lottery winner might have to sell at a loss relative to the issue price. The model can also generate an endowment effect in this case, because even though the lottery winner can potentially land in the loss domain, the size of this loss is buffered by the realization utility that comes from the listing gain. However, the lottery loser does not have this listing gain buffer, and thus experiences the full loss if the stock goes down after listing. The model thus generates a wedge between the winner and the loser, and the associated endowment effect, but this effect gets smaller and smaller as the listing gain approaches zero, since the listing gain buffer is also zero at that point.

As discussed for the Weaver-Frederick model, Figure 1 Panels (a) and (b) do not show a pattern of smaller endowment effects for smaller listing gains. Moreover, in our regression analysis in Table 5, we find that the largest endowment effects occur for IPOs with closer to zero gains, and smaller endowment effects are seen in IPOs with either negative or highly positive listing gains. This is an important rejection of this model - the realization utility of agents depends fundamentally on the size of the listing gain, but our empirical results do not reveal a significant relationship between the listing gain and the endowment effect.

Overall, while a realization utility model may be useful to explain lottery winners' tendency to sell winning versus losing IPO stocks in the first month after listing, it does not provide a good explanation for why lottery winners are so much more likely to hold the IPO stock in our setting (i.e., the endowment effect).

4. Salience Model. The main idea of the salience model, as first suggested in Bordalo et al. (2012) is that agents have distorted probabilities of different states of the world occurring, and this distortion is based on how "salient" the payoffs in that state are. We consider two variants of salience models. The purpose of the first model is to show that a salience mechanism can plausibly generate the behavior of winners post-listing; given this, we pursue the second variant of the model, in a more realistic setup which includes the initial application lottery, to see if salience can generate the endowment effect that we see. 
In the first model (see the Appendix for details), we consider the behavior of the lottery winner after he experiences a high, medium, or low listing gain, and forms distorted beliefs ${ }^{46}$ about the future probability of high, medium or low returns based on this listing gain. When the winner experiences a low listing gain, the salient payoff is the possibility of a large rebound in the stock, and therefore the investor will tend to hold the stock. If the stock has a medium listing return, neither a future gain or loss on the stock is salient and the agent uses the objective probabilities to calculate expected values. If the stock has a high listing gain, the salient outcome is a large drop in the future, so this probability gets overweighted, and the investor tends to sell the stock.

This simple model provides a plausible explanation for the pattern of selling we observe amongst lottery winners in Figures 1c and 1d. Given that this framework is able to explain the behavior of lottery participants subsequent to winning, we go on to develop a model of the IPO lottery itself to understand whether a salience mechanism might also explain why lottery winners are so much more likely to hold the stock than lottery winners.

This model of the IPO lottery follows a similar setup to our model of expectations based reference-dependent model discussed above, with two changes. First, the agent only considers the consumption utility resulting from stock price outcomes, not the gain-loss utility pieces. ${ }^{47}$ Second, agents in the model have distorted probabilities regarding future outcomes of the stock based on the salience of these payoffs.

The general result is that the states of the world where the agent wins the lottery are less salient, because in those cases the agent always receives the listing gain, and (in the short run, such as the day after listing) this swamps the magnitude by which the stock goes up or down. The cases in which the agent loses the lottery are more salient, because lottery losers get a zero payoff under plans where they do not buy the stock, but a potentially high

\footnotetext{
${ }^{46}$ We apply the salience based distortion factor defined in Bordalo et al. (2012), which is a function of the distance between the highest and lowest outcome within each state of the world normalized by the total payoffs across all lotteries within that state.

${ }^{47}$ This is to allow us to focus on the "pure" role of the salience distortion as opposed to the role of gain-loss utility.
} 
payoff under plans where they purchase the stock and it goes up. Furthermore, within the categories of winning or losing the lottery, the state where the stock goes down in price is more salient than the one in which the stock goes up in price. This is because the percentage change in the price when the stock goes down (relative to an equivalent gain) is larger relative to the total possible payoffs in that state of the world.

These patterns imply that a salience based thinker will rank states of the world from highest to lowest salience as follows: 1) lose lottery and stock goes down 2) lose lottery and stock goes up 3) win lottery and stock goes down 4) win lottery and stock goes up. This salience ranking will typically make the never hold plan (i.e., sell if win, do not buy if lose) dominate the endowment effect plan (i.e., hold if win, do not buy if lose). We discuss this result in a more nuanced fashion in the appendix, but essentially, for any model based on probability distortions (such as a salience based model) to produce an endowment effect, it would require the agent to specifically overweight the probability that the stock will go up when they win, but downweight this probability when they lose.

Given this result, we argue that a salience based framework, while a potentially plausible explanation of the winner's behavior in the aftermarket, is unlikely to be able to fully explain the endowment effect.

5. Inattention Model. A key empirical prediction that most of the models above are unable to explain is why lottery losers are so reluctant to buy the stock, irrespective of the size of the listing gain or probability of winning. One possible hypothesis that addresses this failure is that lottery applicants might only pay attention to the stock upon learning that they have won; once they learn they have lost the IPO lottery, the IPO stock might exit their attention set, meaning that it is almost never purchased. Note that this is not the same as the cost-based explanations considered in our discussion of inertia, since what we refer to here is a specific behavioral mechanism of attention allocation (or the lack thereof).

We do not formally model why lottery losers stop paying attention to the stock after they lose the lottery, but suggest two potential microfoundations for this behavior. One is 
that investors may employ the heuristic of first paying attention to stocks in their portfolio before allocating limited attention to other possible stocks. A (related) microfoundation is that winning the stock in the lottery provides "exposure" to the stock, which keeps it in the attention set of winners; but since losers do not receive this exposure, it remains out of the attention set for them (see Bordalo et al. (2015)).

In the Appendix, we present a very simple model of inattention. As above, we assume that lottery losers are completely inattentive to the stock, to match our empirical results. We also assume that some fraction of lottery winners are inattentive to the stock, and will therefore hold the stock either if they are not paying attention to it, or if they are paying attention to it but believe that it is worth more than its current market price. According to this simple model, the endowment effect will increase in the number of winners who are inattentive to the stock, controlling for private valuations.

The ideal test of this theory would be exploit variation in the degree to which winners pay attention to the stock, but this is difficult in the absence of direct observations of attention. Previous work has argued that investors pay attention to stocks in their portfolio that have extreme returns (see for example, Barber and Odean (2008) and Hartzmark (2015)), and we find mixed evidence to support this. Winners are more likely to sell very high return IPOs, consistent with the attention hypothesis. However, they are less likely to sell very low return IPOs, suggesting that a simple attention based model is not adequate to explain the longer run behavior of the winners.

\section{Summary of Theoretical Explanations}

We argue that none of the standard theoretical frameworks studied above can independently provide an adequate description of the endowment effect we find in addition to the other empirical facts that we uncover.

At a minimum, it appears that an important ingredient to explain our results is inattention to the IPO stock on the part of lottery losers - since losers almost never buy the IPO stock, irrespective of the listing gain. However, any such model of inattention has to be 
combined with another model (such as the realization utility model, the Weaver-Frederick model, or the salience model), to meaningfully explain the behavior of the lottery winners in the aftermarket.

\section{Conclusion}

In the absence of important wealth effects or transactions costs, standard economic theories predict a fundamental symmetry: the same person should not make different decisions about whether to hold an asset depending on whether he or she is endowed with the asset. Data on the behavior of applicants to Indian IPO lotteries refutes this prediction. We find that randomly receiving shares in an IPO increases the probability that an applicant holds these shares for many months after the allotment, and that standard factors such as inertia at the portfolio level, wealth effects, taxes, and transactions costs are unlikely to explain these effects.

We highlight two broad contributions of our work. First, our results suggest that endowment type effects may have important implications for naturally occurring asset markets, in addition to the consumer (mugs, pens) and durable goods (sports cards, collector's pins) markets where they have most commonly been studied. Second, our results lend credence to theoretical frameworks, such as those presented in Thaler (1980), Köszegi and Rabin (2006), and Bordalo et al. (2012) where an agents' decision process regarding an asset fundamentally changes once the asset enters their portfolio; lottery winners do not have any standard reasons to value the IPO stock more than lottery losers in our setting, but yet continue to hold it at much higher rates. Although our field context does not allow us to definitively determine which variant of these models best explains our evidence, exploring the empirical validity (in other settings) and general equilibrium implications of this type of buyer/seller divergence appears to be a fruitful area for future research. 


\section{Table 1: Example IPO Allocation Process: Barak Valley Cement iPO AlLOCATION}

\begin{tabular}{|c|c|c|c|c|c|c|c|c|}
\hline $\begin{array}{l}\text { Share Category } \\
c \\
(0) \\
\end{array}$ & $\begin{array}{c}\text { Shares Bid For } \\
\qquad x \\
(1) \\
\end{array}$ & $\begin{array}{c}\text { \# Applications } \\
a_{c} \\
(2) \\
\end{array}$ & $\begin{array}{c}\text { Total Shares } \\
\qquad a_{c} c x \\
(3)\end{array}$ & $\begin{array}{c}\text { Proportional Allocation } \\
\frac{c x}{v} \\
(4) \\
\end{array}$ & $\begin{array}{c}\text { Win Probability } \\
\frac{c}{v} \\
(5) \\
\end{array}$ & $\begin{array}{c}\text { Shares Allocated } \\
(6) \\
\end{array}$ & $\begin{array}{c}\text { \# Treatment group } \\
\frac{c}{v} \times a_{c} \\
(7) \\
\end{array}$ & $\begin{array}{c}\text { \# Control group } \\
\left(1-\frac{c}{v}\right) \times a_{c} \\
(8)\end{array}$ \\
\hline 1 & 150 & 14,052 & $2,107,800$ & 4 & 0.027 & 57,000 & 380 & 13,672 \\
\hline 2 & 300 & 9,893 & $2,967,900$ & 8 & 0.054 & 80,250 & 535 & 9,358 \\
\hline 3 & 450 & 5,096 & $2,293,200$ & 12 & 0.081 & 61,950 & 414 & 4,682 \\
\hline 4 & 600 & 4,850 & $2,910,000$ & 16 & 0.108 & 78,750 & 525 & 4,325 \\
\hline 5 & 750 & 2,254 & $1,690,500$ & 20 & 0.135 & 45,750 & 305 & 1,949 \\
\hline 7 & 1050 & 4,806 & $5,046,300$ & 28 & 0.189 & 136,500 & 910 & 3,896 \\
\hline 8 & 1200 & 2,900 & $3,480,000$ & 32 & 0.216 & 94,050 & 628 & 2,272 \\
\hline 9 & 1350 & 481 & 649,350 & 36 & 0.244 & 17,550 & 117 & 364 \\
\hline 10 & 1500 & 1,302 & $1,953,000$ & 41 & 0.271 & 52,800 & 352 & 950 \\
\hline 11 & 1650 & 266 & 436,900 & 45 & 0.298 & 11,850 & 79 & 187 \\
\hline 12 & 1800 & 317 & 570,600 & 49 & 0.325 & 15,450 & 103 & 214 \\
\hline 13 & 1950 & 174 & 339,300 & 53 & 0.352 & 9,150 & 61 & 113 \\
\hline 15 & 2250 & 20,004 & $45,009,000$ & 61 & 0.406 & $1,217,700$ & 8119 & 11,885 \\
\hline
\end{tabular}

Table 2: Characterizing Lottery Application and Allotment Experience

\begin{tabular}{lllllll}
\hline Treatment Characteristics & & \multicolumn{5}{c}{ Percentile Across Experiments } \\
\cline { 3 - 7 } & Mean & 10 & 20 & 50 & 75 & 90 \\
& $(1)$ & $(2)$ & $(3)$ & $(4)$ & $(5)$ & $(6)$ \\
\hline Application Amount (\$) & 1750.56 & 155.29 & 343.34 & 791.74 & 1397.62 & 2093.73 \\
Probability of Treatment & 0.36 & 0.09 & 0.20 & 0.37 & 0.64 & 0.84 \\
Allotment Value (\$) & 150.29 & 125.60 & 130.33 & 142.76 & 158.53 & 169.40 \\
First Day Gain/Loss (\%) & 39.18 & -7.57 & 6.10 & 17.13 & 37.08 & 87.77 \\
First Day Gain/Loss (\$) & 61.89 & -11.14 & 8.49 & 24.78 & 53.03 & 136.94 \\
Median Portfolio Value (t-2,\$) & 1748.47 & 722.74 & 1088.22 & 1594.63 & 2270.57 & 2999.05 \\
\hline
\end{tabular}




\section{Table 3: Randomization Check}

\begin{tabular}{|c|c|c|c|c|}
\hline & $\begin{array}{c}\text { Treatment } \\
\text { Mean } \\
(1)\end{array}$ & $\begin{array}{c}\text { Control } \\
\text { Mean } \\
(2)\end{array}$ & Difference & $\begin{array}{c}\% \text { Experiments } \\
>10 \% \text { significance } \\
(4)\end{array}$ \\
\hline Applied/Allotted an IPO & 0.379 & 0.379 & 0.000 & 8.97 \\
\hline Cutoff Bid & 0.926 & 0.925 & 0.001 & 10.96 \\
\hline Application by Blocked Amount (ASBA) & 0.047 & 0.048 & -0.001 & 4.43 \\
\hline \multicolumn{5}{|l|}{ States of India } \\
\hline Gujarat & 0.354 & 0.352 & $0.002^{*}$ & 12.27 \\
\hline Maharashtra & 0.212 & 0.211 & 0.000 & 10.44 \\
\hline Rajasthan & 0.150 & 0.151 & -0.001 & 8.87 \\
\hline Delhi & 0.045 & 0.045 & 0.000 & 8.61 \\
\hline Portfolio Value $>0$ & 0.786 & 0.785 & 0.000 & 11.48 \\
\hline IHS Portfolio Value & 6.673 & 6.667 & 0.006 & 13.05 \\
\hline Portfolio Value $=0$ & 0.214 & 0.215 & 0.000 & 10.18 \\
\hline Portfolio Value $=0$ to $500 \$$ & 0.129 & 0.129 & 0.000 & 12.94 \\
\hline Portfolio Value $=500$ to $1000 \$$ & 0.087 & 0.087 & 0.000 & 10.18 \\
\hline Portfolio Value $=1000$ to $5000 \$$ & 0.317 & 0.317 & 0.000 & 8.09 \\
\hline Portfolio Value $>5000 \$$ & 0.252 & 0.252 & 0.000 & 9.39 \\
\hline IHS Gross Transaction Value & 5.342 & 5.350 & -0.008 & 8.61 \\
\hline Transaction Value $=0$ & 0.318 & 0.317 & 0.001 & 9.66 \\
\hline Transaction Value $=0$ to $500 \$$ & 0.175 & 0.175 & 0.000 & 10.96 \\
\hline Transaction Value $=500$ to $1000 \$$ & 0.115 & 0.116 & 0.000 & 9.66 \\
\hline Transaction Value $=1000$ to $5000 \$$ & 0.283 & 0.283 & $0.000^{*}$ & 11.22 \\
\hline Transaction Value $>5000 \$$ & 0.108 & 0.109 & $-0.001^{*}$ & 8.87 \\
\hline \multicolumn{5}{|l|}{ Gross No. of Transactions } \\
\hline No. of Transactions $=0$ & 0.318 & 0.317 & 0.001 & 9.66 \\
\hline No. of Transactions $=1$ to 5 & 0.449 & 0.451 & -0.002 & 8.35 \\
\hline No. of Transactions $=6$ to 10 & 0.116 & 0.115 & 0.000 & 11.22 \\
\hline No. of Transactions $=11$ to 20 & 0.070 & 0.069 & 0.000 & 8.87 \\
\hline No. of Transactions $>20$ & 0.048 & 0.047 & 0.000 & 9.92 \\
\hline Flipper & 0.568 & 0.567 & 0.001 & 13.21 \\
\hline No. of Securities Held & 9.091 & 9.013 & $0.077^{* *}$ & 10.96 \\
\hline IHS Account Age & 3.148 & 3.143 & $0.005^{*}$ & 12.53 \\
\hline New Account & 0.055 & 0.055 & 0.000 & 5.74 \\
\hline 1 Month old & 0.067 & 0.067 & 0.000 & 9.14 \\
\hline 2-6 Months old & 0.191 & 0.192 & -0.001 & 8.87 \\
\hline 7-13 Months old & 0.141 & 0.141 & 0.000 & 8.87 \\
\hline 14-25 Months old & 0.167 & 0.167 & 0.000 & 9.92 \\
\hline$>25$ Months old & 0.375 & 0.373 & $0.002^{* *}$ & 12.01 \\
\hline
\end{tabular}

The sample size is 1,561,497 accounts. The randomization check variables are measured at the end of the month prior to the lottery allotment. ${ }^{* * *},{ }^{* * *}$ denote significance at the 10,5 and 1 percent levels. The flipper dummy takes the value 1 if the account had ever received an IPO and sold it in the month of receiving it. 
Table 4: Effect of Winning IPO LotTery on Ownership Of IPO Stock

\begin{tabular}{|c|c|c|c|c|c|c|c|c|c|}
\hline \multirow[b]{2}{*}{ Dependent Variable: } & & \multicolumn{3}{|l|}{ Listing } & \multicolumn{3}{|c|}{ Months Since Listing } & \multirow[b]{2}{*}{5} & \multirow[b]{2}{*}{6} \\
\hline & & Day & 0 & 1 & 2 & 3 & 4 & & \\
\hline \multirow[t]{3}{*}{ I(Holds IPO Stock) } & $\overline{y_{t r}}$ & 0.700 & 0.624 & 0.542 & 0.519 & 0.497 & 0.484 & 0.474 & 0.466 \\
\hline & $\overline{y_{c t}}$ & 0.007 & 0.010 & 0.014 & 0.016 & 0.015 & 0.015 & 0.016 & 0.016 \\
\hline & $\rho$ & $0.693^{* * *}$ & $0.613^{* * *}$ & $0.527 * * *$ & $0.503^{* * *}$ & $0.482^{* * *}$ & $0.468^{* * *}$ & $0.458^{* * *}$ & $0.449^{* * *}$ \\
\hline \multirow[t]{3}{*}{ Fraction of Allotment } & $\overline{y_{t r}}$ & & 0.645 & 0.576 & 0.562 & 0.543 & 0.533 & 0.529 & 0.522 \\
\hline & $\overline{y_{c t}}$ & & 0.044 & 0.058 & 0.061 & 0.061 & 0.064 & 0.065 & 0.065 \\
\hline & $\rho$ & & $0.601^{* * *}$ & $0.518^{* * *}$ & $0.501^{* * *}$ & $0.481^{* * *}$ & $0.470 * * *$ & $0.464^{* * *}$ & $0.457 * * *$ \\
\hline \multirow[t]{3}{*}{ I(Holds Exactly IPO Allotment) } & $\overline{y_{t r}}$ & & 0.587 & 0.501 & 0.477 & 0.456 & 0.442 & 0.432 & 0.423 \\
\hline & $\overline{y_{c t}}$ & & 0.001 & 0.002 & 0.002 & 0.002 & 0.002 & 0.002 & 0.002 \\
\hline & $\rho$ & & $0.586^{* * *}$ & $0.499^{* * *}$ & $0.475^{* * *}$ & $0.454^{* * *}$ & $0.440^{* * *}$ & $0.429^{* * *}$ & $0.420^{* * *}$ \\
\hline \multirow[t]{3}{*}{ Value of IPO Shares Held (USD) } & $\overline{y_{t r}}$ & & 108.818 & 84.037 & 72.500 & 70.226 & 59.546 & 53.168 & 54.717 \\
\hline & $\overline{y_{c t}}$ & & 7.232 & 8.197 & 7.767 & 7.995 & 7.621 & 7.004 & 7.418 \\
\hline & $\rho$ & & $101.582^{* * *}$ & $75.835^{* * *}$ & $64.727^{* * *}$ & $62.230^{* * *}$ & $51.927^{* * *}$ & $46.164^{* * *}$ & $47.296^{* * *}$ \\
\hline \multirow[t]{3}{*}{ Portfolio Weight of IPO Stock } & $\overline{y_{t r}}$ & & 0.133 & 0.093 & 0.080 & 0.077 & 0.070 & 0.064 & 0.064 \\
\hline & $\overline{y_{c t}}$ & & 0.001 & 0.002 & 0.002 & 0.002 & 0.001 & 0.001 & 0.001 \\
\hline & $\rho$ & & $0.132^{* * *}$ & $0.091^{* * *}$ & $0.079^{* * *}$ & $0.075^{* * *}$ & $0.069^{* * *}$ & $0.063^{* * *}$ & $0.063^{* * *}$ \\
\hline Mean Listing Return & & 42 & & & & & & & \\
\hline Mean Return Over Issue Price & & & 19 & 6 & -1 & 2 & -5 & -6 & -6 \\
\hline Mean Return Over Open Price & & & -15 & -24 & -29 & -27 & -31 & -33 & -33 \\
\hline
\end{tabular}

The sample size is $1,561,497$ accounts in each month. ${ }^{*}, * *, * * *$ denote significance at 10,5 and 1 percent levels. $\overline{y_{t r}}$ denotes the treatment group average, $\overline{y_{c t}}$, the control group average and $\rho$ the coefficient estimated from equation 1. 


\section{Table 5: Long Run Effect of Winning IPO Lottery on Ownership Of IPO Stock}

\begin{tabular}{|c|c|c|c|c|c|c|c|c|c|c|c|}
\hline \multirow[b]{2}{*}{ Dependent Variable: } & & \multicolumn{10}{|c|}{ Months Since Listing } \\
\hline & & 0 & 1 & 4 & 8 & 11 & 12 & 13 & 16 & 20 & 24 \\
\hline \multirow[t]{3}{*}{ I(Holds IPO Stock) } & $\overline{y_{t r}}$ & 0.639 & 0.571 & 0.513 & 0.483 & 0.465 & 0.458 & 0.452 & 0.434 & 0.401 & 0.366 \\
\hline & $\overline{y_{c t}}$ & 0.012 & 0.014 & 0.015 & 0.016 & 0.017 & 0.017 & 0.017 & 0.017 & 0.016 & 0.015 \\
\hline & $\rho$ & $0.628^{* * *}$ & $0.557^{* * *}$ & $0.498^{* * *}$ & $0.467^{* * *}$ & $0.448^{* * *}$ & $0.441^{* * *}$ & $0.434^{* * *}$ & $0.417^{* * *}$ & $0.385^{* * *}$ & $0.350^{* * *}$ \\
\hline \multirow[t]{3}{*}{ Fraction of Allotment } & $\overline{y_{t r}}$ & 0.662 & 0.600 & 0.556 & 0.544 & 0.532 & 0.527 & 0.529 & 0.510 & 0.471 & 0.449 \\
\hline & $\overline{y_{c t}}$ & 0.039 & 0.046 & 0.047 & 0.056 & 0.062 & 0.063 & 0.065 & 0.068 & 0.066 & 0.075 \\
\hline & $\rho$ & $0.623^{* * *}$ & $0.554^{* * *}$ & $0.509^{* * *}$ & $0.488^{* * *}$ & $0.470 * * *$ & $0.464^{* * *}$ & $0.463^{* * *}$ & $0.442^{* * *}$ & $0.405^{* * *}$ & $0.374^{* * *}$ \\
\hline \multirow[t]{3}{*}{ I(Holds Exactly IPO Allotment) } & $\overline{y_{t r}}$ & 0.598 & 0.526 & 0.467 & 0.434 & 0.415 & 0.409 & 0.402 & 0.385 & 0.356 & 0.323 \\
\hline & $\overline{y_{c t}}$ & 0.002 & 0.002 & 0.002 & 0.002 & 0.002 & 0.002 & 0.002 & 0.003 & 0.003 & 0.003 \\
\hline & $\rho$ & $0.596^{* * *}$ & $0.524^{* * *}$ & $0.466^{* * *}$ & $0.432^{* * *}$ & $0.413^{* * *}$ & $0.406^{* * *}$ & $0.400^{* * *}$ & $0.383^{* * *}$ & $0.354^{* * *}$ & $0.321^{* * *}$ \\
\hline \multirow[t]{3}{*}{ Value of IPO Shares Held (USD) } & $\overline{y_{t r}}$ & 119.187 & 93.533 & 57.904 & 34.810 & 22.599 & 20.450 & 18.281 & 32.914 & 33.164 & 30.496 \\
\hline & $\overline{y_{c t}}$ & 7.081 & 7.657 & 5.570 & 4.242 & 3.066 & 2.827 & 2.625 & 4.363 & 4.555 & 5.004 \\
\hline & $\rho$ & $112.111^{* * *}$ & $85.876^{* * *}$ & $52.34^{* * *}$ & $30.572^{* * *}$ & $19.536^{* * *}$ & $17.625^{* * *}$ & $15.658^{* * *}$ & $28.552^{* * *}$ & $28.612^{* * *}$ & $25.495^{* * *}$ \\
\hline \multirow[t]{3}{*}{ Portfolio Weight of IPO Stock } & $\overline{y_{t r}}$ & 0.136 & 0.095 & 0.068 & 0.055 & 0.045 & 0.044 & 0.040 & 0.047 & 0.040 & 0.034 \\
\hline & $\overline{y_{c t}}$ & 0.001 & 0.001 & 0.001 & 0.001 & 0.001 & 0.001 & 0.001 & 0.001 & 0.001 & 0.001 \\
\hline & $\rho$ & $0.135^{* * *}$ & $0.093^{* * *}$ & $0.067^{* * *}$ & $0.054^{* * *}$ & $0.044^{* * *}$ & $0.043^{* * *}$ & $0.039 * * *$ & $0.046^{* * *}$ & $0.039^{* * *}$ & $0.033^{* * *}$ \\
\hline Mean Listing Return & & 52 & & & & & & & & & \\
\hline Mean Return Over Issue Price & & 22 & 9 & -8 & -25 & -46 & -54 & -57 & -51 & -49 & -44 \\
\hline Mean Return Over Open Price & & -18 & -27 & -39 & -52 & -64 & -70 & -72 & -66 & -65 & -62 \\
\hline
\end{tabular}

The sample includes all IPOs that occurred 24 months before the end of our portfolio data in March 2012. The sample size is 1,090,346 accounts in each month. ${ }^{*}, * *, * *$ denote significance at 10,5 , and 1 percent levels. $\overline{y_{t r}}$ denotes the treatment group average, $\overline{y_{c t}}$, the control group average and $\rho$ the coefficient estimated from equation 1. 
Table 6: Heterogeneous Winner Effects By Pre-Existing Account Characteristics

\begin{tabular}{lllll}
\hline Dependent Variable: First Day I(IPO Stock Held) & $(1)$ & $(2)$ & $(3)$ & $(4)$ \\
\hline Winner & $0.762^{* * *}$ & $0.649^{* * *}$ & $0.812^{* * *}$ & $0.779^{* * *}$ \\
\# of IPOs Allotted & $0.001^{* * *}$ & $0.001^{* * *}$ & & \\
$\quad 1$ to 2 IPOs & & & $0.002^{* * *}$ & -0.000 \\
$\quad 3$ to 8 IPOs & & & $0.007^{* * *}$ & $0.003^{* *}$ \\
$\quad>8$ IPOs & & & $0.016^{* * *}$ & $0.009^{* * *}$
\end{tabular}

Winner $x$

$$
\begin{aligned}
& \text { \# of IPOs Allotted } \\
& 1 \text { to } 2 \text { IPOs } \\
& 3 \text { to } 8 \text { IPOs } \\
& >8 \text { IPOs }
\end{aligned}
$$

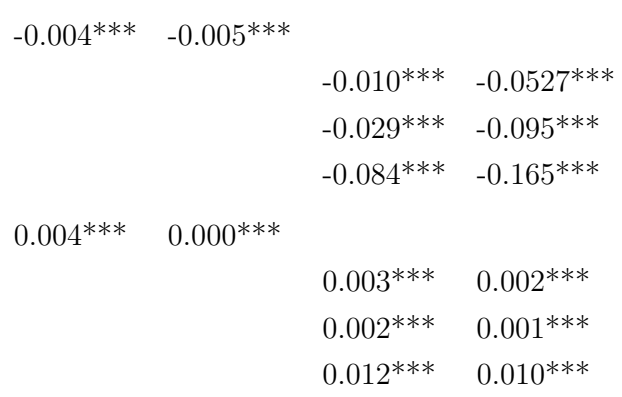

Winner $x$

$$
\begin{aligned}
& \text { \# of Trades Made } \\
& 1 \text { to } 2 \text { trades } \\
& 3 \text { to } 6 \text { trades } \\
& >6 \text { trades }
\end{aligned}
$$

Fraction Past Returns $>$ Listing Returns

0.01 to 0.15

0.16 to 0.50

$>0.50$

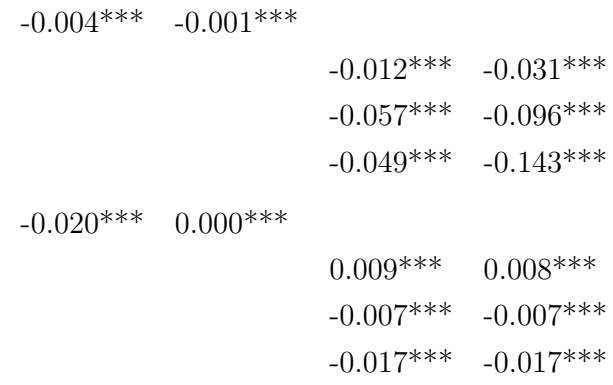

Winner $x$

Fraction Past Returns $>$ Listing Returns 0.01 to 0.15

0.16 to 0.50

$>0.50$

$0.024^{* * *} \quad 0.0017$

$\begin{array}{cc}-0.093^{* * *} & -0.100^{* * *} \\ -0.047^{* * *} & -0.047^{* * *} \\ 0.023^{* * *} & 0.018^{* * *}\end{array}$

Winner $\times$

Listing Returns (\%)

$<=0$

26 to 41 percent

$>41$ percent

$-0.000^{* * *}-0.001^{* * *}$

$-0.212^{* * *}-0.217^{* * *}$

$-0.059^{* * *}-0.053^{* * *}$

$-0.058^{* * *}-0.056^{* * *}$

Winner $x$

Probability of Treatment

33 to 66 percent

$>66$ percent

Controls

Portfolio Size

Age

IPO Share Category Fixed Effects

Adjusted R-squared

Number of observations

\begin{tabular}{llll}
$-0.057^{* * *}$ & $-0.051^{* * *}$ & & \\
& & -0.002 & $0.004^{*}$ \\
& & $-0.039^{* * *}$ & $-0.033^{* * *}$ \\
\hline & & & \\
No & Yes & No & Yes \\
No & Yes & No & Yes \\
Yes & Yes & Yes & Yes \\
0.62 & 0.63 & 0.63 & 0.64 \\
$1,561,497$ & $1,561,497$ & $1,561,497$ & $1,561,497$ \\
\hline
\end{tabular}

Dummies are based on quartile breakpoints of the respective distributions. 


\section{Table 7: Endowment Effect and Non-IPO Small Size Trading Intensity}

\begin{tabular}{|c|c|c|c|c|c|c|c|}
\hline \multirow{2}{*}{$\begin{array}{l}\text { Dep. Var: } \\
\text { Fraction of Allotment Held }\end{array}$} & \multicolumn{7}{|c|}{ Months Since Listing } \\
\hline & 0 & 1 & 2 & 3 & 4 & 5 & 6 \\
\hline & \multicolumn{7}{|c|}{ Trade size $\leq$ IPO allotment value } \\
\hline \multirow[t]{2}{*}{ Month before allotment } & 0.587 & 0.498 & 0.480 & 0.460 & 0.447 & 0.442 & 0.435 \\
\hline & $(0.004)$ & $(0.004)$ & $(0.004)$ & $(0.004)$ & $(0.005)$ & $(0.004)$ & $(0.004)$ \\
\hline \multirow[t]{2}{*}{ In the Month } & 0.594 & 0.485 & 0.435 & 0.383 & 0.481 & 0.461 & 0.376 \\
\hline & $(0.003)$ & $(0.004)$ & $(0.005)$ & $(0.014)$ & $(0.005)$ & $(0.006)$ & $(0.009)$ \\
\hline \multirow[t]{3}{*}{ Upto the End of Month } & 0.594 & 0.525 & 0.507 & 0.475 & 0.463 & 0.459 & 0.451 \\
\hline & $(0.003)$ & $(0.003)$ & $(0.003)$ & $(0.007)$ & $(0.007)$ & $(0.007)$ & $(0.007)$ \\
\hline & \multicolumn{7}{|c|}{ Trades in position size $\leq$ IPO allotment value } \\
\hline \multirow[t]{2}{*}{ Month before allotment } & 0.513 & 0.408 & 0.394 & 0.386 & 0.378 & 0.376 & 0.371 \\
\hline & $(0.010)$ & $(0.010)$ & $(0.011)$ & $(0.012)$ & $(0.012)$ & $(0.012)$ & $(0.012)$ \\
\hline \multirow[t]{2}{*}{ In the Month } & 0.466 & 0.339 & 0.325 & 0.322 & 0.355 & 0.341 & 0.303 \\
\hline & $(0.012)$ & $(0.012)$ & $(0.018)$ & $(0.015)$ & $(0.018)$ & $(0.018)$ & $(0.012)$ \\
\hline \multirow[t]{2}{*}{ Upto the End of Month } & 0.466 & 0.367 & 0.358 & 0.347 & 0.373 & 0.394 & 0.390 \\
\hline & $(0.012)$ & $(0.009)$ & $(0.009)$ & $(0.009)$ & $(0.010)$ & $(0.009)$ & $(0.008)$ \\
\hline
\end{tabular}

The sample includes all those accounts that had at least one trade (buy or sell) that is less than or equal to the IPO allotment value. Position size is estimated at the end of the previous month. Rows named "Upto the End of Month" do not include trades before listing month 0. Standard errors in parenthesis and all coefficients are significant at 1 percent level. 
Figure 1: Fraction Allotment Held and Returns Experience

(a) Listing Returns (\%)

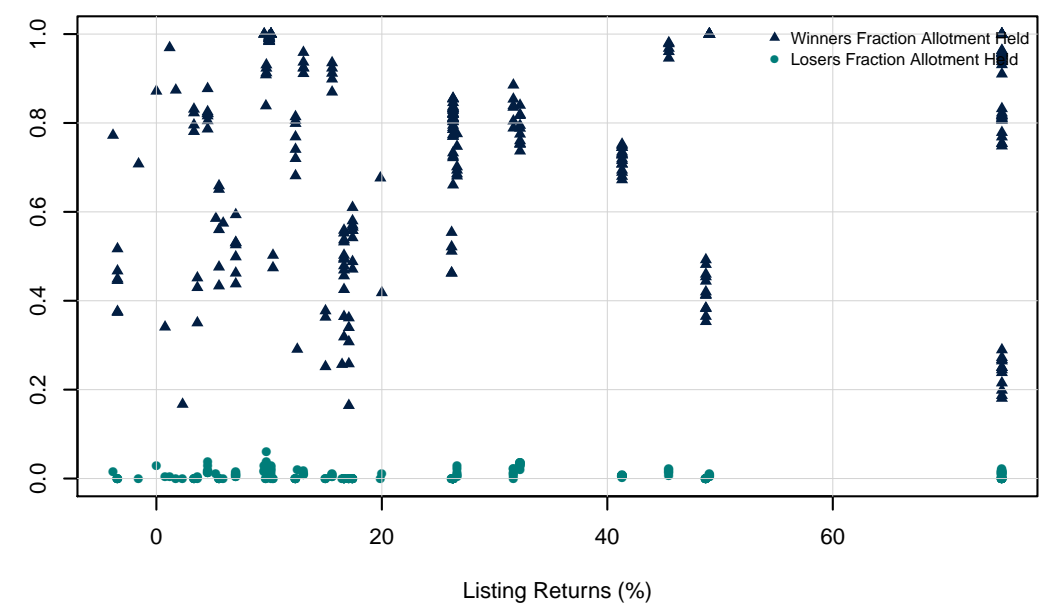

(c) Holding Returns at End of Month One (\%)

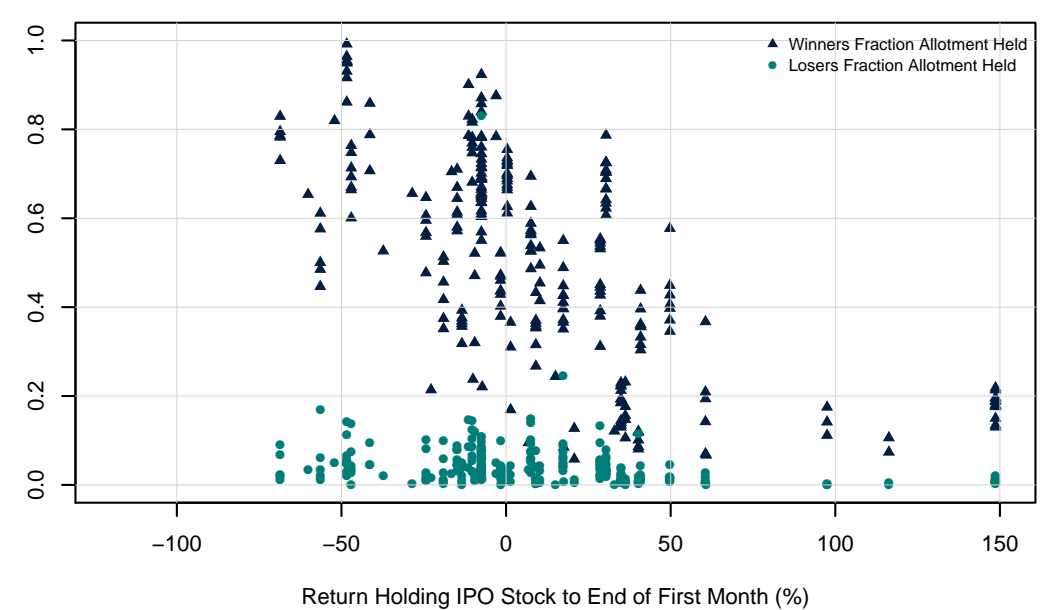

(b) Listing Gain (USD)

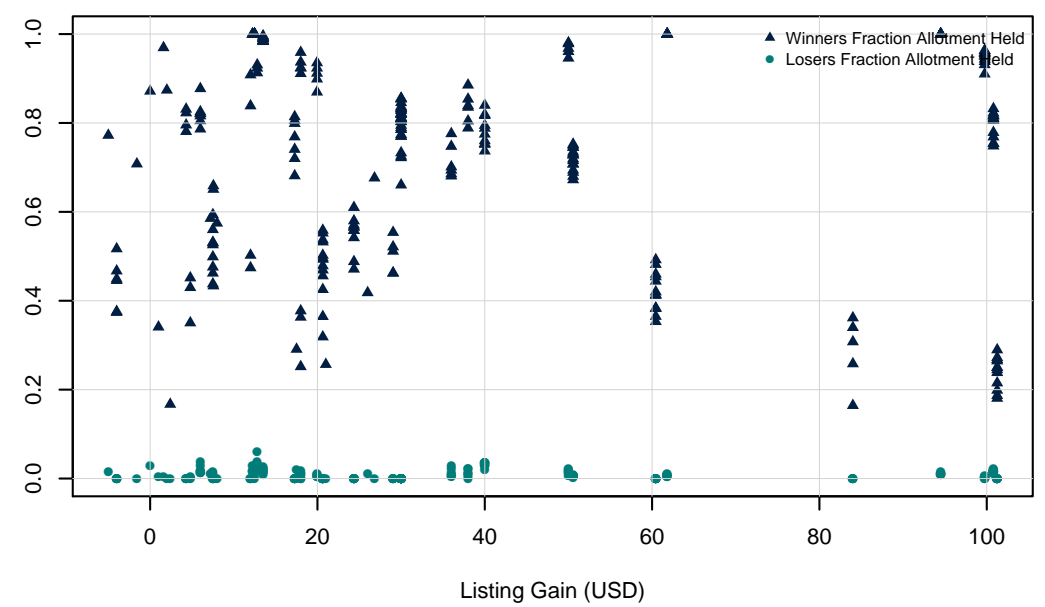

(d) Holding Gain at End of Month One (USD)

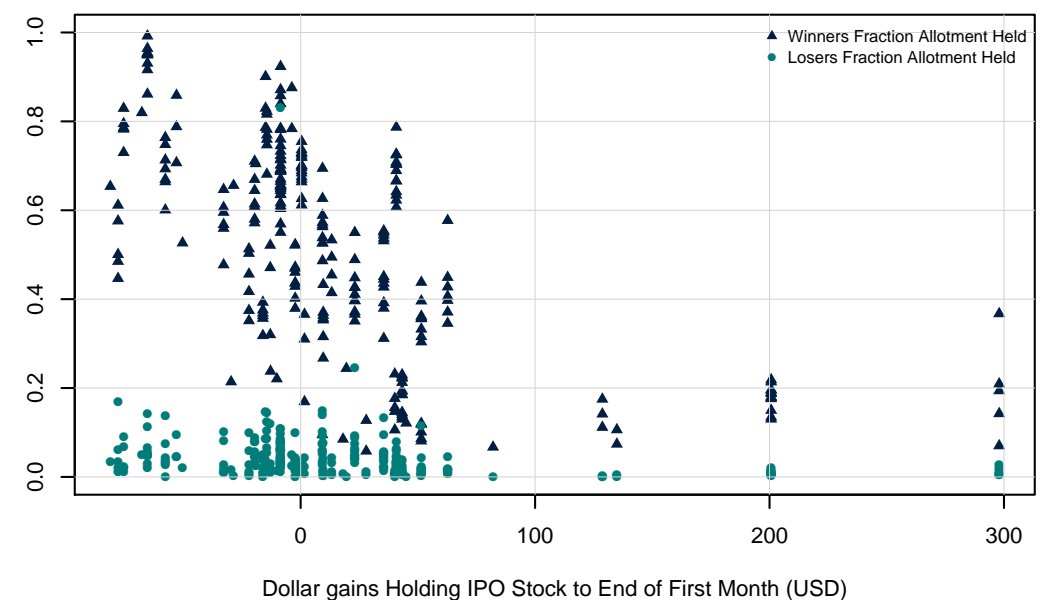

Panels (a) and (b) present estimates at the end of the first day on the y-axis and Panels (c) and (d) present estimates at the end of the first month on the y-axis. 


\section{References}

Abel, Andrew B, Janice C Eberly, and Stavros Panageas, "Optimal inattention to the stock market with information costs and transactions costs," Econometrica, 2013, 81 (4), 1455-1481.

Alvarez, Fernando, Francesco Lippi, and Luigi Paciello, "Monetary Shocks with Observation and Menu Costs," 2013.

Anagol, Santosh and Hugh Hoikwang Kim, "The Impact of Shrouded Fees: Evidence from a Natural Experiment in the Indian Mutual Funds Market," American Economic Review, 2012, 102 (1), 576-93.

_, Vimal Balasubramaniam, and Tarun Ramadorai, "The Effects of Experience on Investor Behavior: Evidence from India's IPO Lotteries," Available at SSRN 2568748, 2015.

Andersen, Steffen, John Y Campbell, Kasper Meisner Nielsen, and Tarun Ramadorai, "Inattention and inertia in household finance: Evidence from the Danish mortgage market," Technical Report, National Bureau of Economic Research 2015.

Angrist, Joshua D and Jörn-Steffen Pischke, Mostly harmless econometrics: An empiricist's companion, Princeton university press, 2008.

Angrist, Joshua D., Parag A. Pathak, and Christopher R. Walters, "Explaining Charter School Effectiveness," American Economic Journal: Applied Economics, 2013, 5 (4), 1-27.

Baker, Malcolm, Joshua Coval, and Jeremy C Stein, "Corporate financing decisions when investors take the path of least resistance," Journal of Financial Economics, 2007, 84 (2), 266-298.

Barber, Brad M. and Terrance Odean, "All That Glitters: The Effect of Attention and News on the Buying Behavior of Individual and Institutional Investors," Review of Financial Studies, 2008, 21 (2), 785-818.

Barberis, Nicholas, "Thirty Years of Prospect Theory in Economics: A Review and Assessment," The Journal of Economic Perspectives, 2013, 27 (1), 173-195.

- and Wei Xiong, "Realization utility," Journal of Financial Economics, 2012, 104 (2), 251-271.

Ben-David, Itzhak and David Hirshleifer, "Are investors really reluctant to realize their losses? Trading responses to past returns and the disposition effect," Review of Financial Studies, 2012, 25 (8), 2485-2532.

Black, Dan A, Jeffrey A Smith, Mark C Berger, and Brett J Noel, "Is the threat of reemployment services more effective than the services themselves? Evidence from random assignment in the UI system," American Economic Review, 2003, pp. 1313-1327.

Bordalo, Pedro, Nicola Gennaioli, and Andrei Shleifer, "Salience in Experimental Tests of the Endowment Effect," The American Economic Review, 2012, 102 (3), 47-52.

_ , _ , and _ , "Competition for attention," The Review of Economic Studies, 2015, p. 48.

Browning, Martin, Francois Bourguignon, Pierre-Andre Chiappori, and Valerie Lechene, "Income and outcomes: A structural model of intrahousehold allocation," Journal of political Economy, 1994, pp. 1067-1096. 
Burbidge, John B., Lonnie Magee, and A. Leslie Robb, "Alternative Transformations to Handle Extreme Values of the Dependent Variable," Journal of the American Statistical Association, 1988, 83 (401), pp. 123-127.

Campbell, John Y., Tarun Ramadorai, and Benjamin Ranish, "Getting Better or Feeling Better? How Equity Investors Respond to Investment Experience," Working Paper 20000, National Bureau of Economic Research March 2014.

Campbell, John Y, Tarun Ramadorai, and Benjamin Ranish, "The Impact of Regulation on Mortgage Risk: Evidence from India," American Economic Journal: Economic Policy, forthcoming, 2015.

Engelmann, Dirk and Guillaume Hollard, "Reconsidering the effect of market experience on the endowment effect," Econometrica, 2010, 78 (6), 2005-2019.

Ericson, Keith M Marzilli and Andreas Fuster, "Expectations as Endowments: Evidence on Reference-Dependent Preferences from Exchange and Valuation Experiments," The Quarterly Journal of Economics, 2011, 126 (4), 1879-1907.

_ and _, "The Endowment Effect," Annual Review of Economics, 2014, 6 (1), 555-579.

Gelber, Alexander, Adam Isen, and Judd B Kessler, "The Effects of Youth Employment: Evidence from New York City Lotteries1," The Quarterly Journal of Economics, 2015, p. 034.

Goette, Lorenz, Annette Harms, and Charles Sprenger, "Randomizing Endowments: An Experimental Study of Rational Expectations and Reference-Dependent Preferences," 2014.

Haigh, Michael S and John A List, "Do professional traders exhibit myopic loss aversion? An experimental analysis," The Journal of Finance, 2005, 60 (1), 523-534.

Hartzmark, Samuel M, "The worst, the best, ignoring all the rest: The rank effect and trading behavior," Review of Financial Studies, 2015, 28 (4), 1024-1059.

Heberlein, Thomas A and Richard C Bishop, "Assessing the validity of contingent valuation: Three field experiments," Science of the Total Environment, 1986, 56, 99-107.

Heffetz, Ori and John A List, "Is the endowment effect an expectations effect?," Journal of the European Economic Association, 2014, 12 (5), 1396-1422.

Hossain, Tanjim and John A List, "The Behavioralist visits the Factory: Increasing Productivity Using Simple Framing Manipulations," Management Science, 2012, 58 (12), 2151-2167.

Jr, Roland G Fryer, Steven D Levitt, John List, and Sally Sadoff, "Enhancing the efficacy of teacher incentives through loss aversion: A field experiment," Technical Report, National Bureau of Economic Research 2012.

Kahneman, Daniel and Amos Tversky, "Prospect theory: An analysis of decision under risk," Econometrica: Journal of the Econometric Society, 1979, pp. 263-291.

_, Jack L Knetsch, and Richard H Thaler, "Experimental tests of the endowment effect and the Coase theorem," Journal of political Economy, 1990, pp. 1325-1348.

Knetsch, Jack L and John A Sinden, "Willingness to pay and compensation demanded: Experimental evidence of an unexpected disparity in measures of value," The Quarterly Journal of Economics, 1984, pp. 507-521.

Köszegi, Botond and Matthew Rabin, "A model of reference-dependent preferences," The Quarterly Journal of Economics, 2006, pp. 1133-1165. 
Levitt, Steven D, John A List, Susanne Neckermann, and Sally Sadoff, "The Behavioralist goes to School: Leveraging Behavioral Economics to Improve Educational Performance," Technical Report, National Bureau of Economic Research 2012.

List, John A., "Does Market Experience Eliminate Market Anomalies?," Quarterly Journal of Economics, 2003, 118 (1), 41-71.

_ , "Neoclassical theory versus prospect theory: Evidence from the marketplace," Econometrica, 2004, 72 (2), 615-625.

_ , "Does Market Experience Eliminate Market Anomalies? The Case of Exogenous Market Experience," The American Economic Review, 2011, 101 (3), 313-317.

Madrian, Brigitte C and Dennis F Shea, "The Power of Suggestion: Inertia in 401 (k) Participation and Savings Behavior," The Quarterly Journal of Economics, 2001, 116 (4), 1149-1187.

Mitchell, Olivia S, Gary R Mottola, Stephen P Utkus, and Takeshi Yamaguchi, "The inattentive participant: Portfolio trading behavior in 401 (k) plans," Michigan Retirement Research Center Research Paper No. WP, 2006, 115.

Nieuwerburgh, Stijn Van and Laura Veldkamp, "Information acquisition and underdiversification," The Review of Economic Studies, 2010, 77 (2), 779-805.

Shefrin, Hersh and Meir Statman, "The disposition to sell winners too early and ride losers too long: Theory and evidence," journal of Finance, 1985, pp. 777-790.

Song, Changcheng, "An Experiment on Reference Points and Expectations," Available at SSRN 2580852, 2015.

Sprenger, Charles, "An endowment effect for risk: Experimental tests of stochastic reference points," Journal of Political Economy, 2015, 123 (6), 1456-1499.

Thaler, Richard, "Toward a positive theory of consumer choice," Journal of Economic Behavior \& Organization, 1980, 1 (1), 39-60.

Weaver, Ray and Shane Frederick, "A reference price theory of the endowment effect," Journal of Marketing Research, 2012, 49 (5), 696-707.

Zeiler, Kathryn and Charles R Plott, "The willingness to pay/willingness to accept gap, the endowment effect, subject misconceptions and experimental procedures for eliciting valuations," American Economic Review, 2004. 